\title{
COLABORACIÓN PÚBLICO-PRIVADA PARA LA REVITALIZACIÓN DE ESPACIOS URBANOS: LA INTRODUCCIÓN DE LOS BUSINESS IMPROVEMENT DISTRICTS EN EL ORDENAMIENTO JURÍDICO ESPAŃOL*
}

\author{
Helena Villarejo Galende \\ Universidad de Valladolid, España \\ helenav@eco.uva.es
}

\section{RESUMEN}

Los Business Improvement Districts (BIDs) son organizaciones de carácter privado, o consorciado con las autoridades locales, creadas para ofrecer una mayor oferta de servicios adicionales dirigidos a la promoción económica y regeneración del área. Desde que nacieran en Canadá, hace más de cuatro décadas, esta nueva forma de colaboración público-privada en el ámbito del gobierno local ha proliferado en distintas ciudades de diferentes países. Este artículo tiene como principal objetivo analizar las experiencias comparadas del modelo BID y examinar, desde un punto de vista jurídico, qué medidas y reformas legislativas serían necesarias para trasladar esta fórmula de colaboración público-privada al ordenamiento jurídico español, así como la problemática que las acompaña.

Palabras clave: Business Improvement Districts, Colaboración públicoprivada, Gobernanza urbana, Derecho, España.

* Este artículo tiene su origen en la ponencia presentada por su autora en el $V$ Congreso Internacional en Gobierno, Administración y Politicas Públicas GIGAPP-IUIOG, organizado por el Instituto Nacional de Administración Pública y celebrado en Madrid los días 29 y 30 septiembre y I octubre de 20 I 4 . El trabajo ha sido elaborado en el marco del Proyecto de Investigación titulado La colaboración público-privada en infraestructuras urbanas como herramienta para contribuir a la recuperación económica y reforzar la sostenibilidad (Ref. DER2OI I-27584), financiado por el Ministerio de Economía y Competitividad (Plan Nacional de I+D+i 2008-20 I I), en el que participan el Instituto de Estudios Europeos y el Departamento de Derecho Público (Universidad de Valladolid), la School of Public Affairs (City University of New York) y el European Institute of Public Administration (EIPA), Maastricht (Holanda). 


\title{
PUBLIC-PRIVATE COOPERATION FOR THE REVITALIZATION OF URBAN SPACES: \\ THE INTRODUCTION OF BUSINESS IMPROVEMENT DISTRICTS IN THE SPANISH LEGAL SYSTEM
}

\begin{abstract}
The Business Improvement Districts (BIDs) are organizations of private nature or in partnership with local authorities, created to offer a greater supply of additional services aiming to propel the economy and regeneration in the area. Ever since their appearance in Canada, over four decades ago, this new form of public-private partnerships in the local government sphere has multiplied in different cities in different countries. The main objective of this article is to analyse comparative experiences in the BID model and to examine, from a legal point of view, which measures and legal reforms would be necessary to transfer this public-private partnership formula to the Spanish legal system, as well as associated problems.
\end{abstract}

Keywords: Business Improvement Districts, Public-private partnership, Urban governance, Law, Spain. 


\section{INTRODUCCIÓN}

Desde hace más de cuatro décadas una nueva forma de colaboración público-privada en el ámbito del gobierno local ha proliferado en las ciudades norteamericanas y ha terminado expandiéndose por innumerables países. Son los conocidos comúnmente como Business Improvement Districts (BIDs), cuya traducción española aproximada sería áreas de mejora empresarial. Se trata de partenariados público-privados - public private partnerships (PPPs) en inglés ${ }^{1}$ - en los que propietarios y empresarios deciden obligarse a hacer una aportación económica colectiva con el objetivo de mantener, desarrollar y promocionar su distrito empresarial.

Tanto desde el punto de vista teórico como práctico, los BIDs han adquirido una enorme importancia debido a la singularidad de su forma de organización, su creciente número y su expansión geográfica, así como los poderes administrativos y económicos que algunos de ellos ejercen.

El rápido crecimiento de los BIDs responde a diversos factores socioeconómicos y políticos. Es clara la influencia del declive de los centros de las ciudades unida a un urbanismo disperso generado por el desarrollo de una extensa red de autopistas; la proliferación de nuevos formatos comerciales; los problemas de organización y financiación de los municipios; o la tendencia a recurrir a sociedades o partenariados públicoprivados para llevar a cabo la revitalización urbana (Hoyt y Gopal-Agge 2007: 948). En línea con la última de las causas citadas, podría argumentarse que bajo la expansión de la fórmula de los BIDs subyace la creencia de que las ciudades existen para crear oportunidades individuales de acumulación de la riqueza y de que los líderes económicos son los mejor cualificados para dirigir las políticas públicas hacia tal fin. Esta condición ha jugado un papel central en la legislación y la política de los gobiernos locales en Estados Unidos (Briffault 1999: 470) y también en Canadá (Bradford 2003: 1020-1022). Las fórmulas de gobierno basadas en la colaboración público-privada reflejan la creencia neoliberal de que los fallos del Estado son probables, cuando no inevitables, y que, en consecuencia, para mejorar

I Existe una amplísima literatura sobre los PPPs que adolece de una cierta imprecisión conceptual (Brinkerhoff y Brinkerhoff 20II), pues el término partenariado es abordado desde muy diferentes perspectivas que incluyen desde fórmulas contractuales (Johnston and Romzek 2005), acuerdos entre la Administración y organizaciones no gubernamentales (Brinkerhoff 2002) o, más genéricamente, la cooperación entre el gobierno local y una comunidad (Krishna 2003, World Bank 2005). No resulta sencillo, pues, encontrar una definición que abarque los diferentes enfoques. Con todo, los PPPs podrían ser comúnmente considerados como "una forma de cooperación entre actores públicos y privados, de carácter duradero, en la que ambos actores desarrollan conjuntamente productos y/o servicios, y donde se comparten riesgos, costes y beneficios" (Kickert et al. 2000). 
la eficacia en la prestación de los servicios públicos, es necesario involucrar a la sociedad civil, al sector privado (Jessop 2002: 454-455). Junto a ello, los BIDs encajan a la perfección en las ideas de promoción y fortalecimiento de la comunidad propugnadas por el llamado Nuevo Urbanismo (Katz 1994): ofrecen un foro a sus miembros para debatir sobre la definición de su esfera pública, animan a la peatonalización de las calles, defienden el comercio de proximidad, trabajan para atraer visitantes y consumidores, favoreciendo así el carácter abierto del distrito (Davies 1997: 212-215).

Los BIDs han de ser contextualizados en el fenómeno de la globalización económica (Lloyd et al. 2003: 296) y en las consecuencias que está teniendo en las ciudades que ahora compiten en un mercado global, buscando una ventaja competitiva para mejorar su imagen mediante el city marketing o iniciativas privadas de regeneración urbana (Amin y Thrift 1995), y que han modificado sus políticas locales con nuevos enfoques basados en el emprendimiento, la innovación y la mercantilización (Lovering 1995). En términos generales, en los últimos años, la globalización ha traído consigo un elevado nivel de pragmatismo, en el sentido de búsqueda de soluciones que funcionen (Lloyd et al. 2003: 296). Esto entronca directamente con el nuevo papel que están desempeñando los gobiernos locales, fortalecidos por una parte con los procesos de descentralización, pero al tiempo debilitados por la creciente gestión privada de los servicios esenciales (Borja y Castells 1996). La emergencia de los PPPs, la puesta en práctica de proyectos de regeneración urbana o de city marketing de carácter especulativo o empresarial y la inclusión de las élites económicas en la gobernanza urbana contemporánea lleva a algunos autores a hablar de nuevos gobernantes urbanos (Harvey 1989, Kavaratzis 2007), entre los que se encontrarían los BIDs (Cook 2009).

Por todo ello, los BIDs pueden ser contemplados como un paradigma de la evolución de la política urbana en los últimos ańos, en el contexto más amplio de los procesos de neoliberalización (Brenner y Theodore 2002, Peck y Tickell 2002, England y Ward 2007, Brenner et al. 2010, Eick 2012), dentro de una amalgama de nuevas formas de regulación basadas en la aceptación del mercado como el modelo dominante de prestación de servicios y desarrollo económico y la asunción de que la Administración debería estar menos involucrada en la prestación directa de los servicios (Ratcliffe et al. 1999). Los BIDs ponen de manifiesto las tendencias de descentralización y privatización que retan a los gobiernos locales. En la medida en que reemplazan al municipio en la prestación de servicios públicos, su creación -sostiene Mallet (1994: 284)- es expresión de un fallo del gobierno local. Puesto que el poder público hace dejación de sus funciones, la iniciativa privada sustituye a la iniciativa pública, en 
una suerte de privatización por desgaste o encubierta. Ahora bien, no debe olvidarse que los BIDs son agentes públicos, creados por designación municipal precisamente para rellenar los vacíos dejados por una prestación ausente o deficiente de servicios públicos en aquellas municipalidades incompetentes o ineficaces. En este sentido, representan claramente un cambio en la forma de gobernar de la ciudad, basada en la coalición entre los actores públicos y privados.

Las tendencias de descentralización y privatización son un reto para los gobiernos locales. Los gobiernos federales y estatales o regionales transfieren un gran número de tareas a los gobiernos locales. Al mismo tiempo, estos, al igual que el resto de los niveles de gobierno, están entregando muchas funciones al sector privado (Davies 1997: 187). ¿Cómo preservar los intereses públicos al tiempo que se incrementa la confianza en el sector privado?

Curiosamente, en una época en la que no new taxes (no a nuevos impuestos) es un mantra político y en la que los votantes rechazan la creación de nuevos tributos mientras que aprueban las limitaciones o deducciones impositivas, los BIDs han sido creados para imponer el pago de tasas adicionales y son los empresarios y propietarios sujetos a la nueva imposición los que lideran su constitución (Briffault 1999: 366). Para los gobiernos locales, los BIDs ofrecen un mecanismo de financiación y de mejora de los servicios locales prestados en el área, sin necesidad de elevar los impuestos generales.

En España, son varias las administraciones públicas, entidades privadas y partidos políticos que en los últimos tiempos -motivados, sin duda, por las acuciantes necesidades de financiación derivadas de la crisis- vienen manifestando interés por las posibilidades de desarrollo de este modelo en España. Este artículo tiene como principal objetivo analizar las experiencias comparadas del modelo BID y examinar, desde un punto de vista jurídico, qué medidas y reformas legislativas serían necesarias para trasladar esta fórmula de colaboración-público privada al ordenamiento jurídico español, así como la problemática que las acompaña.

El artículo se estructura en dos grandes apartados. En el primero, se efectúa una caracterización de los BIDs, ofreciendo una perspectiva general del modelo, a partir de la configuración que ha ido adoptando en Canadá, Estados Unidos, Reino Unido y Alemania. Su naturaleza, su origen y transferencia internacional, el proceso de constitución, la forma de financiación y las actividades que desarrollan estas organizaciones son examinadas desde una perspectiva crítica que ayude a poner de relieve sus fortalezas y sus debilidades. Una vez efectuada esta panorámica de los 
BIDs, en el segundo apartado, se analiza el proceso de transferencia que se está iniciando en España, partiendo de los recientes movimientos sociales y políticos en favor de la incorporación de la figura al ordenamiento jurídico español para, a continuación, ofrecer una propuesta sobre la naturaleza jurídica, la forma de constitución y el régimen de financiación que deberían adoptar este tipo de organizaciones en España. Se valoran las reformas legislativas que habría que emprender en atención a los importantes obstáculos que plantean, principalmente desde el punto de vista de la distribución de competencias - ¿quién y cómo habría de regular?- y desde la perspectiva constitucional en atención a los obstáculos que podría encontrar esta figura en relación con el derecho de libertad de asociación. Y, en definitiva, se pretende ahondar en la problemática que genera la hipotética translación de los BIDs a España.

\section{CARACTERIZACIÓN GENERAL DEL MODELO BID}

Es preciso señalar que existen notables diferencias entre los BIDs a lo largo y ancho del planeta en cuanto a su organización y funcionamiento, en su configuración legal y las potestades que de facto ejercen. Debido a estas variaciones, el fenómeno BID resulta bastante complejo, si bien existen suficientes similitudes que -aun sin soslayar su enorme diversidadpermiten realizar una caracterización general del modelo.

\section{DeFINICIÓN}

El término BID es usado indistintamente en la literatura académica para denominar tanto las áreas geográficas como las organizaciones que las gestionan (Morçöl et al 2008: 2). Y, así, los BIDs pueden ser definidos como distritos o zonas geográficas, permitidos por la legislación estatal, autorizados por los gobiernos locales, que se promueven y gestionan por los empresarios o los propietarios de los locales de negocio mediante fórmulas de autofinanciación, con el objeto de ofrecer servicios públicos en las áreas en que actúan (Morçöl y Wolf 2010: 906). Y, también, como

[...] organizaciones dirigidas privadamentey autorizadas públicamente que prestan servicios públicos complementarios dentro de un área geográfica determinada, gracias a la generación de ingresos anuales provenientes del pago de contribuciones de manera obligatoria por parte de los propietarios de los locales y/o empresarios (Hoyt y GopalAgge 2007: 946).

Para entender este modelo es clave tener en cuenta que son los propios propietarios o empresarios de una zona geográfica delimitada los que tras una votación acuerdan por mayoría dotarse de un nivel extra de servicios 
públicos mediante la imposición del pago de un recargo impositivo o de una cuota a todos los propietarios y/o empresarios ubicados en la zona (Mitchell 1999: 6). Resulta interesante que en el proceso de formación de un BID aparezca siempre como una característica común que sean los empresarios y los propietarios de locales de negocios, que normalmente manifiestan una aversión hacia los impuestos, los que voluntariamente decidan ser gravados con una carga extra para recaudar fondos que mejoren la gestión de una determinada zona (Ratcliffe y Branagh 2004: 379, Brooks 2008). Resumidamente, estas organizaciones actúan bajo el principio quid pro quo: Los empresarios/propietarios se obligan a pagar contribuciones extra para recibir servicios extra (Villarejo 2007: 12). En definitiva, el BID es un mecanismo de organización y financiación usado por los empresarios y propietarios de una zona comercial o industrial para desarrollarla económicamente (Houstoun 1999).

Autores como Briffault (2010) afirman que el crecimiento de los BIDs en las últimas décadas sugiere que hay un gran valor en un modelo institucional que permite obtener ingresos adicionales de los propietarios o empresarios de una zona concreta que se destinan a la financiación de programas y actividades dentro de su ámbito geográfico, más que depender por entero del gobierno local para la provisión de los servicios públicos. Los BIDs permiten que las comunidades asuman sus necesidades y les proporcionan servicios adicionales. Y, más significativamente, los BIDs posibilitan que sean los propios miembros de la comunidad quienes decidan cuáles son sus prioridades y preferencias y determinen exactamente qué servicios van a suplementar y qué actividades desarrollarán (Briffault 2010: 22).

Si bien la diversidad de los BIDs es sorprendente, resulta igualmente llamativa la similitud entre las tareas que la mayoría de estas organizaciones desarrollan: limpieza de las calles, remoción de graffitis, recolección de basuras, seguridad suplementaria, mejoras del mobiliario urbano, embellecimiento del espacio público (flores y árboles), iluminación especial, organización de eventos, promoción de una señalización uniforme del distrito empresarial, y, en general, marketing y branding de la zona. Algunos de los BIDs más ambiciosos han tratado de resolver problemas de aparcamiento o de tráfico, o incluso han lidiado con la problemática de los usos urbanísticos, el transporte, servicios sociales para los sin techo ${ }^{2}$.

Los BIDs se centran predominantemente en mantener y mejorar el paisaje urbano, contribuyendo a que los espacios públicos resulten más atractivos (Briffault 1999: 394-409).

2 Es el caso del Center City BID en Filadelfia, analizado por Morçöl (20 I0: 279). 


\section{ORIGEN Y EXPANSIÓN DE LOS BIDs}

El modelo surge como una iniciativa del sector privado para revitalizar los centros urbanos. Desde la década de los años cuarenta, muchos empresarios de distintas ciudades norteamericanas aunaron sus esfuerzos para combatir el fenómeno de la descentralización urbana y evitar que empresarios y consumidores abandonaran sus actividades en los centros de las ciudades en favor de la periferia urbana. El fenómeno fue en aumento cuando los pequeńos comerciantes del centro urbano sufrieron el impacto de la instalación de los malls o centros comerciales en el extrarradio urbano. El auge del fenómeno metropolitano y la consiguiente aparición de ciudades dormitorio con bajos niveles de equipamiento comercial, el incremento de las ventas debido a la mayor capacidad de compra de los consumidores, la creciente motorización, la congestión del centro de las ciudades y las consiguientes dificultades de accesibilidad o el aumento progresivo de los precios del suelo en los centros urbanos, fueron algunas de las razones que motivaron la aparición de nuevas fórmulas comerciales con un denominador común: su gran superficie de actuación, su excelente accesibilidad en vehículo privado y su localización periférica (Villarejo 2008a: 87).

Las asociaciones de pequeños comerciantes recurrieron a la realización de actividades promocionales (organización de eventos, facilidades para el aparcamiento, mejora de los escaparates, entre otros) como estrategia para tratar de atraer clientes e inversores al centro urbano, con el objetivo de incrementar las ventas y el valor de sus propiedades. Intentaron desarrollar una gestión unitaria de los centros urbanos "a imagen y semejanza de los malls" (Villarejo 2007: 16).

A mediados de los sesenta, un pequeño grupo de empresarios en Toronto, Canadá, tuvo una ocurrencia para solventar el problema que generaban los denominados free-riders (libres de carga), es decir, los miembros del colectivo que, sin cooperar económicamente en su financiación, se beneficiaban de las actividades y mejoras que la asociación llevaba a cabo gracias a las aportaciones voluntarias de sus miembros. Para evitar la presencia de estos polizones, exploraron la posibilidad de crear una entidad autónoma, gestionada privadamente, con la capacidad de imponer el pago de una contribución especial sobre todos los propietarios comerciales del distrito para financiar las iniciativas locales de revitalización (Houstoun 2003: 68). A tal efecto, era necesario elaborar legislación habilitante. El 17 de diciembre de 1969 la provincia de Ontario aprobó la sección 379g de la Ley Municipal y, poco después, el Ayuntamiento de la ciudad de Toronto aprobó la Ordenanza Municipal N. ${ }^{\circ}$ 170-70 que permitió que el primer BID del mundo, el Bloor West Village, pudiera constituirse legalmente 
(Hoyt 2006: 229). En las últimas cuatro décadas, más de 300 Business Improvement Areas (BIAs) han sido creados en Canadá, con el importante apoyo del gobierno federal (Ward 2006: 57). Más de 200 están situados en Ontario y en torno a 70 en el Greater Toronto Area (Hernández y Jones 2006: 795).

En Estados Unidos, los BIDs emergen en la década de los ochenta, cuando la legislación de algunos estados permitió que se establecieran dentro de las ciudades ${ }^{3}$. Por ejemplo, en 1981, la Asamblea legislativa del Estado de Nueva York otorgó a sus ciudades el poder para crear BIDs y, un año después, la ciudad de Nueva York aprobó dos ordenanzas que permitían su instauración. A finales del siglo XX, veinte años después de que comenzaran su andadura, había más de 400 BIDs en 42 estados, situándose el 64\% en sólo cinco: California, New York, New Jersey, North Carolina y Wisconsin (Mitchell 1999: 6). Sin embargo, estos datos no coinciden con los facilitados por otros autores que estiman que la cifra de BIDs en Estados Unidos es mucho más elevada: entre 1000 y 2000 (Briffault 1999: 366, Hochleutner 2003: 374; Lloyd et al. 2003: 300). Sólo en la ciudad de Nueva York hay en la actualidad 69 BIDs ${ }^{4}$.

Últimamente, la fórmula está siendo transferida a otros países como el Reino Unido, Irlanda, Alemania, Holanda, Sudáfrica, Australia, Nueva Zelanda, Serbia, Albania, Colombia, Brasil, Suiza, Suecia, Japón, poniendo de manifiesto un fenómeno global de movilidad de las políticas urbanas (Ward 2006, Cook 2008, Peck y Theodore 2010, Peyroux et al. 2012, McCann y Ward 2013). En Europa, los BIDs se importan por primera vez en el Reino Unido, con la aprobación de la Local Government Act de 2003 (aplicable en Inglaterra y Gales) y su consiguiente desarrollo legislativo aprobado en 2004 y 2005, respectivamente ${ }^{5}$ con posterioridad, fue aprobada la Planning etc. Act 2006 (para Escocia) ${ }^{6}$ y, finalmente, la

3 Aunque el primer BID de Estados Unidos fue el Downtown Development Corporation (DDC) establecido en 1974 en New Orleans. Hoy, todos los estados americanos, excepto Wyoming, han aprobado algún tipo de legislación que habilita para la creación de los BIDs (Mitchell 2008: 3).

4 Véase la página web del Ayuntamiento de Nueva York destinada a los BIDs, disponible en: http://www.nyc.gov/html/sbs/html/neighborhood/bid.shtml [28-o8-20I4].

5 Parte 4 de la Local Government Act 2003 (http://www.legislation.gov.uk/ ukpga/2003/26/pdfs/ukpga_20030026_en.pdf) [I 5-I 2-2014]. Para Inglaterra: The Business Improvement Districts (England) Regulations 2004, aprobadas mediante Statutory Instrument 2004 No. 2443 (http://www.legislation.gov.uk/uksi/2004/2443/ pdfs/uksi_20042443_en.pdf) [I 5-I 2-20 I 4]. Para Gales: The Business Improvement Districts (Wales) Regulations 2005, aprobadas mediante Statutory Instrument 2005 No. I3I2 (http://www.legislation.gov.uk/wsi/2005/I3 I 2/pdfs/wsi_2005 I3 I 2_ mi.pdf) [I 5-I 2-20I4].

6 La normativa escocesa sobre BIDs puede ser consultada en http://www.bids- 
Business Improvement Districts Act 2013, para Irlanda del Norte ${ }^{7}$. Los BIDs en el Reino Unido encontraron su antecedente en los Town Centre Management (TCM), una fórmula de colaboración público-privada en el ámbito local que se desarrolló por todo el país a partir de los noventa y que, de manera similar a los BIDs, implicaba la prestación de servicios de limpieza y marketing, aunque eran financiados por los gobiernos locales y las contribuciones voluntarias de los empresarios de la zona (Cook 2008, Lloyd y Peel 2008). A finales del año 2013, había más de 150 BIDs en funcionamiento en el Reino Unido (British BIDs 2013), no sólo en grandes ciudades (en torno a 25 en Londres), sino también en ciudades de menor tamaño y áreas rurales. Desde que se pusiera en marcha el primer BID en el Reino Unido en 2005, el crecimiento ha sido constante, con una media superior a 18 nuevos BIDs cada año (Ward y Cook 2014).

En Alemania, fue la ciudad-estado de Hamburgo la pionera en aprobar una normativa específica sobre BIDs en diciembre de $2004^{8}$. Poco después, los dos primeros BIDs de Hamburgo (BID Sachsentor y BID Neuer Wall) entraron en funcionamiento. En enero de 2007, se introdujo un nuevo párrafo en el Código Federal de Urbanismo (Baugesetzbuch-\$171f BauGB), bajo la denominación iniciativas privadas en el desarrollo urbano (Private Initiativen zur Stadtentwicklung). Sobre la base de este precepto, los dieciséis Länder alemanes pueden ahora aprobar leyes específicas para promover iniciativas privadas dirigidas al desarrollo y regeneración de determinadas áreas urbanas (Friesecke 2006, Kreutz 2009, Brenner 2010, Eick 2012). Hasta ahora, ocho de ellos lo han hecho ya; un total de 30 BIDs están funcionando en Alemania y cerca de 100 están en proceso de constitución, lo que ha llevado a algunos autores a hablar de la BIDización de las ciudades alemanas (Eick 2012; 2014).

\section{Procedimiento PARA SU CONSTITUCión}

Aunque el modelo varía de un país a otro o incluso de un Estado a otro en el caso de estados federales, los BIDs son habitualmente creados por designación municipal de conformidad con la autoridad que para ello les confiere la legislación habilitante en el nivel estatal. En Estados Unidos, el establecimiento de un BID exige la aprobación municipal, pero el impulso

scotland.com/index.php?option=com_content\&view=article\&id=22\&Itemid $=$ I I I

7 Vid. http://www.niassembly.gov.uk/Assembly-Business/Legislation/PrimaryLegislation-Current-Bills/Business-Improvement-Districts-Bill/ [I 5-I 2-20 I 4].

8 La denominada Ley para fortalecer las áreas comerciales, de servicios y de negocios de 28 de diciembre de 2004 (Gesetz zur Stärkung der Einzelhandels-, Dienstleistungs- und Gewerbezentren, GSED), disponible en: http://www.juris.de/jportal/portal/page/ bshaprod.psml? showdoccase = I \&doc.id=jlr-ZentrSt\%C3\%A4rkGHArahmen\&doc. part $=X \&$ doc.origin $=b s \& s t=\operatorname{lr}[$ I 5 -I 2-20I4] . 
para su creación proviene normalmente de los propietarios o empresarios de la zona, que, además, determinan las fronteras del distrito y desarrollan su plan de financiación y de actuaciones (Briffault 1999: 369). En la mayoría de las leyes estatales se establece un procedimiento en dos pasos para la creación de un BID. En primer lugar, ha de celebrarse una votación entre los interesados (propietarios y comerciantes o empresarios) que autorice la formación de un BID en el área. Y, en segundo término, el gobierno local tiene que aprobar una ordenanza (legislación local) mediante la que se constituye formalmente el BID y se establecen sus fronteras, funciones, presupuesto y modo de financiación. Lo habitual es que estas fases impliquen numerosas audiencias públicas, debates y negociaciones encaminadas a asegurar un notable respaldo local o, al menos, la falta de oposición significativa (Hochleutner 2003: 378, NYCDSBS 2003a: 6-7).

En el Reino Unido, los BIDs deben superar un doble test en una votación en la que cada empresario obligado a pagar el gravamen (levy en la legislación británica) en el área propuesta tiene derecho a voto. Primero, la propuesta de BID tiene que recibir el voto afirmativo de la mayoría de votantes. Y, segundo, el valor del alquiler de los locales de negocios (rateable value) de los empresarios que votaron a favor debe ser más elevado que el de aquellos que votaron en contra (Cook 2009). En el caso de Inglaterra y Gales, son los empresarios (business occupiers) del distrito quienes votan; mientras que en Escocia, también votan los propietarios, siempre que estén obligados a pagar el levy. Otra diferencia en el proceso para la constitución de un BID en Escocia es que en las votaciones se exige la concurrencia de empresarios y/o propietarios que al menos representen un $25 \%$ tanto en términos numéricos como en porcentaje del valor gravado, como garantía del mandato democrático de los BIDs (Ward y Cook 2014).

En Alemania, son los propietarios quienes deciden: ellos pagan y ellos votan. De acuerdo con la legislación de Hamburgo (GSED) la propuesta inicial de BID necesita ser respaldada por tan sólo un 15\% de los propietarios del área prevista, que representen al menos un $15 \%$ de la superficie total de todas las propiedades del área (expresadas en metros cuadrados). Una vez que el business plan - plan de funcionamiento y financiación del BIDpresentado con los mencionados apoyos es aceptado por la administración pública, la solicitud se somete a información pública durante un mes y se celebra entonces una votación entre todos los propietarios de la zona, que contempla un derecho a veto (Brenner 2010: 222). Si los propietarios afectados que explícitamente rechazan la propuesta representan menos de un tercio del total, y de nuevo en términos cuantitativos y cualitativos, el BID será públicamente aprobado (mediante la intervención de la administración pública) y todos los propietarios incluidos dentro de los 
límites del BID estarán obligados a pagar un gravamen adicional basado en el valor de sus propiedades (Kreutz 2009: 308).

En la mayoría de los países, la vida del BID se limita a un número escaso de ańos (habitualmente cinco), pero lo cierto es que rara vez se disuelven. Por el contrario, los BIDs se renuevan periódicamente mediante procesos de reautorización, previstos en la legislación de cada Estado, que siguen casi siempre el mismo procedimiento que las votaciones para la creación inicial (Houstoun 2003: 33, Kreutz 2009: 308, Ward y Cook 2014).

La existencia de estos procesos de votación, tanto para la creación como la renovación de los BIDs, hace que sus defensores hablen del carácter democrático y transparente de estas organizaciones. Estas afirmaciones, no obstante, han sido cuestionadas por algunos autores que consideran críticamente que los BIDs sólo son democráticos y transparentes para sus miembros y no para la comunidad en su conjunto (Hochleutner 2003; Briffault 2010).

\section{RÉGIMEN DE FINANCIACIÓN}

La fase de delimitación del área es muy importante en la formación de un BID. Téngase presente que el modelo se basa esencialmente en una subdivisión territorial de una ciudad, en la cual todos los propietarios y/o empresarios incluidos en ella están sujetos al pago obligatorio de contribuciones adicionales para su mantenimiento, desarrollo y promoción (Briffault 1999: 368).

En Estados Unidos, la fórmula empleada para la financiación del BID recibe el nombre de assessment y no es legalmente un impuesto, sino más bien una tasa o contribución especial que los propietarios pagan en contraprestación de los servicios que reciben, si bien tales servicios no son exactamente públicos sino privados. Es un tipo de exacción que recae sobre la propiedad a cambio de los beneficios directamente asociados a la fórmula (Hochleutner 2003: 379). Ésta es la principal fuente de financiación de los BIDs y puede variar de cientos a miles de dólares anuales dependiendo del valor de los locales, del tamaño del distrito y de la fórmula recaudatoria (Mitchell 1999: 17). Así, por ejemplo, en la ciudad de Nueva York, las cantidades anualmente recaudadas varían entre los US\$53.000 del 180th Street ${ }^{9}$ y los casi US\$ 16.000.000 del Alliance for Downtown New York $^{10}$. Entre todos, invierten en la mejora de Nueva York más de US\$

9 Disponible en http://www.nyc.gov/html/sbs/html/neighborhood_development/ bid_directory.shtml?bid=35 [I0-08-2014].

Io Disponible en http://www.nyc.gov/html/sbs/html/neighborhood development/ bid directory.shtml?bid=32 [I0-08-20I4]. 
105.000.000 anualmente (Gross 2013) ${ }^{11}$.

La cantidad exigida a cada miembro del BID es calculada de diversas formas, dependiendo de factores como el tamaño del establecimiento, su fachada, el valor tasado, el uso al que se destina, entre otros, o de una combinación de todas ellas (Mitchell 1999). En Nueva York, de media, cada propietario paga aproximadamente un recargo del $6 \%$ sobre su real estate tax charge (equivalente al impuesto sobre bienes inmuebles en España) (NYCDSBS 2003b: 2). La carga fiscal recae principalmente sobre los propietarios de locales comerciales (el grupo que recibe los beneficios tangibles del incremento de la actividad empresarial local). De hecho, los propietarios residenciales a menudo no pagan o pagan solamente cantidades simbólicas y no es frecuente que las organizaciones no lucrativas o entidades públicas ubicadas en el área estén obligadas a pagar (Hochleutner 2003: 379).

La capacidad impositiva especial que, consiguientemente, otorga a los miembros de un área geográfica específica servicios públicos suplementarios confiere al modelo BID una autonomía considerable en la resolución de problemas. Y, sin embargo, no es la única fuente de financiación. En torno al 50\% de los BIDs en Nueva Zelanda y Estados Unidos reciben donaciones voluntarias o pagos en especie por parte de las propiedades que, dentro del distrito, están exentas del pago de contribuciones.

En Toronto, el sistema de financiación se basa en la autonomía de cada Business Improvement Area (BIA) para determinar cuál es la cantidad que cada año quiere invertir en la mejora y promoción de la zona. Una vez determinado el presupuesto anual por el Board of Management del BIA y aprobado posteriormente por El Ayuntamiento, la cantidad que cada miembro del BIA tiene que abonar se determina mediante una fórmula proporcional. Y así, cada miembro está obligado a pagar una parte del presupuesto anual de la organización, que se calcula de manera proporcional en relación con el importe global del impuesto sobre la propiedad de la totalidad del BIA ${ }^{12}$. El Ayuntamiento de la ciudad se encarga de la recolección y ulterior devolución al BIA de las cantidades. Además, El Ayuntamiento desarrolla programas anuales para asistir económicamente a los BIAs mediante subvenciones y ayudas públicas (Hoyt y Gopal-

I I Disponible en http://www.nyc.gov/html/sbs/html/neighborhood_development/ bids.shtml [I0-08-20I4].

I 2 Por ejemplo, si el impuesto sobre la propiedad que paga un propietario comercial es US $\$ 6.000$ anuales, el montante total de los impuestos sobre la propiedad que pagan todos los miembros del BIA es US\$2.000.000 y el presupuesto anual del BIA es US\$ I00.000, entonces ese propietario comercial tiene que pagar anualmente un recargo (levy) de US\$ 300. 
Agge 2007: 949), enmarcadas en cuatro programas diferentes: festivales y eventos, investigación comercial y de mercados, realización de murales y mejoras del mobiliario urbano ${ }^{13}$.

En el Reino Unido, la diferencia más importante en relación con el modelo norteamericano viene determinada porque tanto en Inglaterra como en Gales son los empresarios (los arrendatarios de los locales de negocios) quienes están obligados a realizar una contribución obligatoria que denominan levy, que es recaudada por las autoridades locales como un recargo sobre los impuestos que pagan anualmente (Cook 2008). En Escocia, se sigue la misma lógica, aunque el parlamento escocés ha permitido que cada BID en particular pueda decidir si también los propietarios están obligados a pagar. No obstante, en el momento actual el gobierno inglés está valorando la necesidad de modificar la legislación para incluir a los propietarios en los esquemas de financiación de los BIDs ${ }^{14}$. El tipo del recargo impositivo es determinado por cada BID y lo habitual es que no supere el $1 \%$ del rateable value. Las cantidades recaudadas a través del recargo impositivo oscilan entre las $£ 22.400$ de London New Addington y las $£ 2.814 .000$ de London New West End Company (British BIDs 2013: 5).

En Alemania, el recargo que están obligados a pagar los propietarios de la zona se calcula sobre la base del valor catastral de sus propiedades, sin que pueda exceder del 10\% del valor inicial de la propiedad (Brenner 2010). La recaudación de los tributos es realizada por la administración tributaria del Land, que tras detraer la cantidad correspondiente en concepto de gastos de gestión del tributo, transfiere el montante restante a la organización que gestiona el BID. Las cantidades recaudadas varían de unos BIDs a otros. El Neuer Wall BID de Hamburgo ha invertido cerca de $€ 6.000 .000$ en la zona hasta el año 2010 y ha aprobado ya un presupuesto adicional de $€$ 2.300.000 para el período 2011-2016 .

I 3 En la página web del Ayuntamiento de Toronto, puede encontrarse información detallada sobre estos programas (http://www.toronto.ca/bia/financial_incentive_ programs.htm) [I0-08-20I4]. Entre las condiciones para recibir estas ayudas, la ciudad de Toronto exige, por ejemplo, firmar un compromiso de no discriminación.

I 4 En respuesta a la recomendación del informe elaborado por Mary Portas (20 I I) y mostrando el convencimiento de los potenciales beneficios de la inclusión de los propietarios en los BIDs, el gobierno lanzó una consulta pública en julio de 2013 sobre la base del documento Property Owners and Business Improvement Districts: Formalising the Role of Property Owners, Who Are not Ratepayers, in Business Improvement District Schemes (Department for Communities and Local Government 20I3). Vid. https://www.gov.uk/government/consultations/property-owners-andbusiness-improvement-districts [IO-08-20I4].

is Vid. http://www.bid-neuerwall.de [Io-08-20I4]. 


\section{LOS SERVICIOS PRESTADOS}

Las contribuciones especiales son recaudadas normalmente junto con los impuestos locales sobre la propiedad por las autoridades municipales y, después, son transferidas al órgano de gobierno del BID para que las destine al ejercicio de actividades o prestación de servicios en beneficio de la organización. Aunque las actividades desarrolladas por los BIDs varían significativamente de unos a otros, incluso dentro de una misma localidad, tienden a centrarse en: a) la limpieza y mantenimiento del espacio público, proporcionando servicios básicos y mejorando la apariencia del paisaje urbano; b) la seguridad de los espacios públicos y de los negocios; y c) el marketing o promoción económica del área del BID y la organización de eventos para competir con otras áreas dentro y fuera de la ciudad (Hochleutner 2003: 380, Ward 2007, Mitchell 2008).

Los BIDs prestan servicios que complementan los tradicionales prestados por el municipio (especialmente, limpieza y mantenimiento de las calles, retirada de graffitis, recogida de basuras, pavimentación de aceras, señalización e iluminación, instalación de bancos, papeleras, árboles, flores, entre otros). Junto a las tareas de limpieza y mantenimiento del mobiliario urbano, la mayor parte de los BIDs proporcionan algún tipo de servicio de seguridad complementario en el espacio público del distrito, por ejemplo, mediante la contratación de personal de seguridad privada y la instalación de cámaras de vigilancia para prevenir el delito y conseguir que empresarios, trabajadores y consumidores del área se sientan más seguros ${ }^{16}$.

Buena parte de las actividades de los BIDs se centran en la promoción y marketing del distrito empresarial. Los BIDs pretenden hacer de su área geográfica un lugar más atractivo para el desarrollo de la actividad económica y para ello, no sólo se ocupan de las mejoras del espacio físico, sino que prestan asistencia directa a los negocios, promocionan comercialmente el distrito, reclutan nuevas empresas, tratan de consolidar a las ya instaladas, atraen turistas y consumidore Los BIDs se publicitan a través de campañas promocionales, publirreportajes en medios de comunicación, páginas web, elaboración de guías de los establecimientos asociados, folletos informativos; realizan campañas de descuentos en fechas señaladas; otorgan vales a los clientes en los aparcamientos públicos o facilitan servicios de autobús; y tratan de amenizar la zona con la celebración de eventos especiales como

I6 La actitud de las patrullas de seguridad privada de los BIDs ha sido cuestionada en numerosas ocasiones. Algunos de sus excesos han provocado conflictos legales que están generando una notable jurisprudencia, en la que los tribunales ya han condenado a algunas de estas organizaciones -es el caso de Grand Central Partnership en Nueva York- por la violación de los derechos civiles (Barr 1997). 
conciertos y festivales. En gran medida, el plan estratégico de un BID se basa en una imagen y un diseño estandarizados. Para promocionar y mejorar la imagen suele instalarse una señalización específica del distrito.

En menor medida, los BIDs se han ocupado de la regulación de los espacios públicos en los que operan, fundamentalmente mediante el control de las actividades económicas informales. Y, así, su empeño por limpiar y embellecer las calles ha conducido a una cuasicriminalización de la venta ambulante. Como lobby, los BIDs han propuesto y logrado que las autoridades locales regulen el cuándo, el dónde, el qué y el cómo de la venta en las calles. En Nueva York, por ejemplo, la acción de los BIDs ha conseguido la restricción del número de licencias para vender legalmente en la calle y, así, las ordenanzas locales prohíben la venta ambulante en la mayor parte del Midtown Manhattan y en el Financial District ${ }^{17}$. Junto a las actividades económicas informales, se han tratado de regular, además, otras actividades consideradas no deseadas en el distrito, porque deterioran the quality of live de la ciudad: prostitución, pornografía, sex shops- El mayor ejemplo de esto lo constituye el BID de Times Square en Nueva York que, desde que se constituyó en 1992, ha experimentado una espectacular reconversión, que ha transformado el antiguo sex district en un destino turístico familiar. E, incluso, en aras de la salvaguardia de la seguridad pública, ciertos BIDs se han ocupado de limitar ciertas formas de activismo político en las calles (protestas, manifestaciones) que consideran transgresoras y molestas para el espacio cuidadosamente diseñado del BID (Clough y Vanderbeck 2006: 2280).

\section{LA HIPOTÉTICA INTRODUCCIÓN DEL MODELO EN ESPAÑA}

El modelo BID podría servir para solucionar los problemas que encaran las asociaciones empresariales que desde hace años actúan en España para la dinamización comercial de los centros urbanos, conocidas como centros comerciales abiertos $(\mathrm{CCAs})^{18}$. En el momento presente, una de las principales amenazas para el buen funcionamiento de los CCAs es la falta de cooperación por parte de los pequeños comerciantes del área. Es elevado el número de establecimientos que, pudiendo afiliarse al CCA por ubicarse dentro de su perímetro, deciden no hacerlo. Eso supone que

I7 La regulación de la venta ambulante en esta ciudad es muy compleja. La primera enmienda de la Constitución de los Estados Unidos (libertad de expresión) protege a los artistas callejeros, vendedores de prensa, discos, libro. No obstante, incluso esta modalidad de venta ha sido restringida en determinadas calles. Los veteranos de guerra tienen un tratamiento especial y, sin embargo, también han sido expulsados de las zonas BID (Benson 2006: 57-58).

I 8 Este modelo sería aplicable, además de a los centros urbanos, a otros entornos donde haya actividad económica, como los polígonos industriales o destinos turísticos. 
hay un importante colectivo empresarial que se está beneficiando de las acciones dirigidas a dinamizar y revitalizar el comercio del centro urbano, pero que no contribuye en modo alguno a su sostenimiento (el problema de los free riders). La falta de implicación de los afectados se une a los problemas de financiación derivados del alto grado de dependencia de las ayudas y subvenciones públicas (decrecientes) que los CCAs tienen en la actualidad ${ }^{19}$. Así, el actual modelo organizativo, basado en formas asociativas tradicionales, no parece el más adecuado para que los CCAs sigan avanzando.

Como el modelo se basa esencialmente en una subdivisión territorial de una ciudad, en la cual todos los empresarios y/o propietarios incluidos en ella están obligados a contribuir económicamente a su mantenimiento, desarrollo y promoción, los problemas de financiación podrían verse resueltos, asegurando su sostenibilidad.

Desde el punto de vista jurídico, trasladar la fórmula BID al ordenamiento jurídico español implicaría importantes reformas legislativas que hicieran posible que todos los establecimientos comerciales (de servicios, en general) ubicados en el área designada, obligatoriamente contribuyeran a su financiación.

\section{EL CAMINo ESPAŃOL HACIA LOS BIDs}

Es necesario reconocer el importante papel que ha jugado la Asociación Española para la Gerencia de Centros Urbanos (AGECU) en la introducción del modelo BID en España20. Ya en sus estatutos fundacionales de 1999 se establecía como objetivo de la asociación

Perseguir la creación y perfeccionamiento de un marco legal tanto en el Estado Español, como en sus Comunidades Autónomas o Ayuntamientos posibilite la creación de las Gerencias de Centro Urbano adoptando los modelos más avanzados internacionales, tales

I9 La gran mayoría de los CCAs (un 97\%) cuenta con un modelo de financiación mixto, integrado por aportaciones públicas, cuotas que abonan los socios y otros ingresos privados procedentes de la prestación de servicios, patrocinios, eventos, entre otros. Las aportaciones privadas son insuficientes -casi el $70 \%$ cobran una cuota mensual de sus asociados inferior a $€ 30$ por mes; en un I0\% es incluso inferior a $€$ Io, y la dependencia del dinero público es muy elevada. Véanse los resultados del Estudio sobre la gestión de centros urbanos en España, que explora los datos obtenidos en una encuesta efectuada a 84 de estas organizaciones españolas (Rovira 20 I I).

20 De manera similar, la doctrina ha destacado el papel de la International Downtown Association (IDA) en la expansión de los BIDs en Estados Unidos y la Association of Town Centre Management (ATCM) en la introducción del modelo en el Reino Unido (Ward y Cook 20I4). 
como los Business Improvement Districts (BIDs), que permitan la autofinanciación, la participación democrática y la sostenibilidad de las iniciativas.

A lo largo de los últimos años, AGECU ha organizado jornadas y viajes internacionales para conocer y difundir el modelo de gestión e impulsar su implantación en España ${ }^{21}$.

También la Confederación Española de Comercio ha manifestado su interés por la figura en diversas ocasiones. En junio de 2010, se organizó en Burgos el VI Encuentro del Comercio Español, en el que Jerry Mitchell, profesor de la City University of New York (CUNY) y reconocido experto internacional sobre los BIDs, impartió una conferencia y se debatió sobre la oportunidad de trasladar el modelo a España 22 . Otras asociaciones empresariales se han mostrado partidarias de los BIDs. En el año 2012, en el marco del Plan de Dinamización Comercial de la Comunidad de Madrid, la Confederación Empresarial de Madrid (CEIM) y la Confederación de Empresarios de Comercio Minorista, Autónomos y de Servicios de la Comunidad de Madrid (CECOMA) propusieron la creación de distritos BID en la capital de España. Pero no sólo se han desarrollado acciones en el ámbito del comercio, también la Coordinadora Española de Polígonos Empresariales (CEPE), en el año 2011, propuso al Ministerio de Industria desarrollar un proyecto de Ley de Competitividad de las Áreas Empresariales basado en los BID.

En el año 2010, se creó un grupo de expertos en el marco del Programa de dinamización comercial urbana y creación de gerencias de centros urbanos comerciales (2010-2011), promovido por la Dirección General de Comercio Interior (Ministerio de Economía) y el Consejo Superior de Cámaras de Comercio. En las conclusiones del citado grupo de expertos se analizan las posibles alternativas de evolución del modelo de gestión de las zonas comerciales urbanas españolas y, tras examinarse distintas experiencias internacionales (Estados Unidos, Canadá, Reino Unido y Alemania) en la gestión de los centros y zonas comerciales, se toman los BIDs como modelo de referencia. Más adelante, en el año 2012, se constituyó en el seno del Ministerio de Economía y Competitividad el Grupo de Trabajo sobre Comercio y Ciudad, del que forman parte la Secretaría de Estado de Comercio y la Confederación Española de Comercio, que demandó la creación de un nuevo marco legal para la gestión de los centros urbanos que les permitiera obtener una financiación estable y obligatoria para todos

2 I Consúltese el sitio de AGECU en: http://www.agecu.es/

22 La web del Encuentro es http://www.lafuerzadelcomercio.es/html/programa.html. El papel de las conferencias y congresos en la expansión internacional del modelo ha sido también destacado por la doctrina (Cook y Ward 2012). 
los negocios del área.

Los partidos políticos también han comenzado a manifestar su interés por los BIDs. Ya en 2008, en el Programa Electoral del Partido Socialista podía leerse:

Impulsaremos el desarrollo de los Centros comerciales abiertos y ejes comerciales en las ciudades como elementos de atracción comercial frente a la periferia urbana. Para ello, desarrollaremos un marco normativo que permita a los mismos dotarse de estructuras de gerencia $\mathrm{y}$ de ingresos propios. Impulsaremos el compromiso de las diferentes entidades públicas y privadas con el desarrollo del Centro comercial abierto (PSOE 2008:172).

Desde el año 2012, las propuestas por parte de diferentes grupos políticos, tanto en el ámbito estatal como autonómico, no han dejado de sucederse. En febrero de 2012, el Grupo Parlamentario Socialista registró en el Parlamento de Catalunya una Proposición de Ley para regular las áreas de promoción de la economía urbana (ver Parlament de Catalunya 2012: 14-22). En abril de 2012, Convergència i Unió (CiU) registró una Proposición no de Ley para su debate en la Comisión de Hacienda del Congreso de los Diputados en la que se pedía al gobierno que permitiera reformar la Ley Reguladora de las Haciendas Locales con el fin de facilitar la colaboración público privada en la financiación de la gestión y promoción de los centros comerciales urbanos (Congreso de los Diputados 2012b: 16-17). En abril de 2012, el Partido Popular de Madrid presentó en el marco de su 15 Congreso Regional una propuesta para la implantación de los BIDs en España. En junio de 2012, el Partido Nacionalista Vasco presentó una Proposición no de Ley en el Parlamento Vasco en la que se solicitaba la introducción de los BIDs, como medida para ayudar a la reactivación del comercio vasco, paliar en lo posible su crisis y recuperar su fortaleza y dinamismo. En septiembre de 2012, el Gobierno de la Generalitat de Catalunya aprobó la memoria previa al inicio de la tramitación del Anteproyecto de Ley por el cual se regulan las denominadas Comunitats de Promoció d'Iniciatives Empresarials (CPIE). En diciembre de 2012, la Dirección General de Comercio Interior del Ministerio de Economía elaboró un borrador de Anteproyecto de ley sobre colaboración público-privada en la gestión de áreas de promoción de las iniciativas empresariales (APIEs). En marzo de 2013, el Partido Popular de la Comunitat Valenciana presenta a la Mesa de Les Corts una Proposición no de Ley sobre la implantación de modelos de gestión conjunta en las áreas comerciales urbanas de la Comunitat. En octubre de 2013, el PSC-PSOE presentó una propuesta en el Parlament de Catalunya para dedicar parte del impuesto a las grandes superficies a crear Áreas de 
Promoción Económica Urbana (APEU) de acuerdo con el proyecto de Ley que meses atrás habían presentado. En diciembre de 2013, esta propuesta se debatió en el Parlament y fue desestimada. En marzo de 2014, el Grupo Parlamentario Popular en el Congreso de los Diputados presentó una proposición no de Ley para instar al gobierno a impulsar la gestión de áreas comerciales urbanas, para su debate en la Comisión de Economía y Competitividad, tomando como referencia el modelo de los BIDs, desarrollando los programas de incentivos y propiciando todos los cambios normativos que para ello fuese necesario (Congreso de los Diputados 2012a: 18-19). En el momento actual, la opción gubernamental por la adopción de los BIDs parece decidida, a juzgar por las declaraciones que se vierten en el Plan Integral de Apoyo a la Competitividad del Comercio Minorista de España 2014, relativas a la necesidad de estudiar un modelo normativo para el reconocimiento, organización y desarrollo de los centros comerciales abiertos en España tomando como referencia el modelo de los BIDs (Ministerio de Economía y Competitividad 2014), así como por algunas noticias aparecidas en prensa (El País 2014a, 2014b).

A finales de mayo de 2014, el Ayuntamiento de Madrid aprobó una Ordenanza de Dinamización de Actividades en Dominio Público mediante la que se crean las zonas de iniciativa emprendedora (ZIEs), que permiten que los empresarios de cualquier eje comercial, constituyéndose previamente en asociaciones administrativas de contribuyentes, puedan solicitar la ordenación de contribuciones especiales con el objeto de asegurar la financiación de servicios para promover actuaciones de dinamización en el espacio público, que repercutan en la mejora de la actividad económica y comercial en dichos ámbitos (Ayuntamiento de Madrid 2014a: 6-14).

\section{UNA PROPUESTA HIPOTÉTICA DE INCORPORACIÓN DE LOS BIDS COMO COMUNIDADES PARA LA GESTIÓN DE ÁREAS DE PROMOCIÓN DE LAS INICIATIVAS EMPRESARIALES}

Aunque muchas de las propuestas mencionadas anteriormente no han sido más que meras declaraciones de intenciones o tentativas que se han convertido en papel mojado, se evidencia un claro movimiento a favor de la incorporación del modelo BID al ordenamiento jurídico español, que se ha intensificado en los últimos meses. No obstante, aún no está nada claro en qué términos podrían trasladarse los BIDs a España y qué modificaciones legislativas serían necesarias. Las páginas que siguen son un intento de dar respuesta a esas preguntas, pergeñando un hipotético marco normativo que pudiera dar cobertura a un modelo de colaboración entre el sector público y el sector privado para la creación, desarrollo y fortalecimiento de áreas urbanas constituidas con el objetivo de promover las iniciativas empresariales y revitalizar el entorno urbano. 
El objetivo del modelo sería fortalecer y desarrollar áreas empresariales para el fomento de la economía y la mejora del abastecimiento a la población de bienes y servicios. Si se pretende que el modelo pueda desarrollarse en toda Espańa con una cierta homogeneidad, podría adoptarse un marco legal de carácter estatal que estableciera la posibilidad de constituir comunidades empresariales que, mediante una organización y responsabilidad financiera propias, pudieran adoptar medidas que contribuyeran a mejorar la situación de las empresas y a hacer más atractivas las áreas urbanas en las que desarrollan su actividad. Estas áreas podrían denominarse APIEs, adoptando una denominación que ya ha adquirido una cierta trayectoria. Son áreas (se trata por lo tanto de territorios delimitados donde se concentran actividades comerciales y de servicios con un alto dinamismo) para la promoción (es decir, con finalidad de promover actuaciones de gestión de este espacio colectivo, mediante servicios, entre otros) de las iniciativas (define un marco de innovación y corresponsabilidad) empresariales (con lo que se enfatiza el carácter de la primacía de los empresarios implantados en el área para el desarrollo de las actividades $)^{23}$. Las comunidades constituidas para gestionar dichas áreas podrían denominarse CAPIEs (Comunidades para la gestión de Áreas de Promoción de las Iniciativas Empresariales). Al margen del acierto o no de esta denominación, a lo largo de este artículo se utilizarán las siglas CAPIEs para hacer referencia a los hipotéticos BIDs españoles.

Descartada la vía de creación de una nueva figura impositiva, el modelo propuesto se caracteriza, en primer lugar, por la legitimidad que se le otorga a una comunidad empresarial para que pueda dinamizar económicamente un área urbana en interés propio, pero cuyas acciones concurren con otras de interés público, al que, por lo tanto, también sirven aquellas; en segundo lugar, es necesario crear un ente para gestionar todas esas actividades, con capacidad de autofinanciación.

Si se quieren reconocer jurídicamente los BIDs en el ordenamiento jurídico español, el protagonismo, no sólo la iniciativa, lo deben tener los empresarios interesados en promocionar un área determinada de la ciudad o núcleo urbano. En consecuencia, se configuraría una comunidad de intereses, como una nueva entidad colaboradora de la Administración, de carácter no lucrativo, con personalidad y capacidad jurídicas. En líneas generales, su creación se produciría mediante autorización municipal,

23 Véanse las Conclusiones del grupo de expertos, dentro del Programa de Dinamización Comercial Urbana y la creación de una red de Gerencias de Centros Comerciales Urbanos en España, impulsado por el entonces Ministerio de Industria, Turismo y Comercio y el Consejo Superior de Cámaras de Comercio de España (201 I). Disponible en http://es.slideshare.net/villarejoh/conclusiones-grupo-de-expertosareas-promocin-iniciativas-empresariales [I 5-I 2-20I4]. 
previa petición y respaldo democrático mayoritario de los miembros de la comunidad empresarial. Una vez creada, la adscripción a la entidad de los empresarios de la zona sería obligatoria, así como el pago de las cuotas, que podrían ser reclamadas por la vía de apremio. Su vigencia sería temporal y su renovación exigiría las mismas mayorías que su constitución.

Las CAPIEs se constituirían para prestar servicios complementarios o adicionales de los que presta la administración pública, como por ejemplo, la limpieza y el saneamiento, el mantenimiento de la seguridad pública, la instalación y mantenimiento del mobiliario urbano, iluminación, campañas de imagen, organización de eventos y otros servicios dirigidos a promocionar, revitalizar y hacer más atractivas las áreas urbanas en las que actúan. Todos estos servicios prestados por las CAPIEs habrían de ser -es preciso insistir en ello-complementarios o adicionales de los prestados por el municipio, y, por lo tanto, concurrentes con estos, pero en ningún caso sustitutivos.

\section{NATURALEZA JURÍDICA: COLABORACIÓN PÚBLICO-PRIVADA}

Es claro que los BIDs tienen una naturaleza híbrida entre lo público y lo privado. Estamos ante una forma de colaboración público-privada, en modo alguno desconocida en el derecho español. Nos encontramos ante agentes colaboradores o delegados de la Administración. Es ésta una técnica jurídico-política perfectamente reconocida en el ordenamiento jurídico europeo. No debe resultarnos extraño que la Administración delegue determinadas funciones públicas de carácter administrativo en entidades particulares, sin que por ello éstas pierdan su naturaleza jurídicoprivada, ni mucho menos se conviertan en administraciones públicas. El poder público las corresponsabiliza y les encomienda el ejercicio de algunas funciones -aunque no su titularidad-, así como la financiación necesaria para llevarlas a cabo, reservándose determinadas competencias de control para verificar que esa gestión o ejercicio se acomodan a las exigencias de derecho público.

Pero, ¿cómo caracterizar a las organizaciones encargadas de gestionar las denominadas APIEs? ¿Serían asociaciones privadas sin ánimo de lucro? ¿Entidades de carácter administrativo? ¿Corporaciones de derecho público?

Sea cual sea la calificación legal que se le otorgue, como dicen los ingleses, las leyes lo pueden todo menos cambiar a un hombre en mujer y, por lo tanto, según la célebre frase del profesor Ramón Parada (1999: 352), "[...] tampoco pueden alterar el sexo o la naturaleza de las instituciones, diciendo que es privado un ente cuyo carácter público se evidencia en la contemplación de sus ostensibles atributos, de su régimen jurídico". A mi 
juicio, el carácter administrativo de estas entidades es evidente. Tal y como yo las concibo, las CAPIEs serían entidades colaboradoras que tendrían carácter administrativo y que dependerían de la administración actuante, en este caso El Ayuntamiento, que se encargaría de aprobar su constitución y estatutos y fiscalizar su actividad.

\section{¿SERÍA NECESARIO ELABORAR UNA REgUlaCión EX NOVO O baSTARÍA CON ADAPTAR LA NORMATIVA YA EXISTENTE?}

Con independencia de su calificación formal, estamos ante un supuesto de lo que Tomás-Ramón Fernández (2008) califica como autoadministración, es decir, gestión autónoma por los propios interesados de funciones inicialmente administrativas. Un fenómeno, según el autor, característico del moderno derecho administrativo, que se da en numerosos sectores (comunidades de regantes, asociaciones administradoras de concentraciones forestales, colegios profesionales, juntas de compensación, entidades urbanísticas de conservación, entre otros). Una alternativa a la gestión burocrática de funciones públicas, que son delegadas dentro de ciertos límites en los interesados, cuyas organizaciones se convierten así en agentes descentralizados de la Administración.

No es algo desconocido por completo en el ordenamiento jurídico español. Así, por ejemplo, aunque previstas para otros fines, pueden encontrarse similitudes en las comunidades de propietarios o en las entidades colaboradoras en la gestión urbanística. Va cobrando carta de naturaleza el ánimo de los particulares de participar y colaborar con sus respectivos ayuntamientos en el diseño y construcción de lo que será la ciudad de todos, asumiendo una cuota de responsabilidad en lo que en puridad es tarea de todos y que, bien ejecutada, a todos ha de procurar satisfacciones.

El problema que estádetrás de la financiación de este tipo deorganizaciones es el carácter de la adscripción de los empresarios del área considerada. Como se ha examinado en la primera parte de este artículo, mientras se mantenga la voluntariedad, siempre habrá alguien que no pague a pesar de que saque provecho de las acciones colectivas. La reforma legislativa que exigiría la adopción del modelo BID afecta a dos importantes ámbitos del ciudadano: su libertad y su patrimonio. Restringir la libertad de alguien imponiéndole su adscripción o incorporación obligatoria a una comunidad de intereses requiere Ley Formal. E imponer a cualquier ciudadano una contribución personal o patrimonial también exige Ley Formal. Por lo tanto, la Ley resulta imprescindible. Siendo como es necesaria la Ley para regular la figura, habría de procurarse que su inserción en el ordenamiento jurídico existente resultara sencilla, lo menos traumática posible, sin 
generar estropicios.

¿Quién tendría que regular? ¿Quién determinaría el régimen jurídico de estas entidades en un país descentralizado como España: el Estado, las comunidades autónomas, los municipios? La respuesta a esta pregunta depende del tipo de regulación que se lleve a cabo. A mi entender, podría elaborarse una regulación básica de carácter estatal, circunscrita al establecimiento de los requisitos mínimos. Puesto que el asunto abordado es fundamentalmente de carácter municipal, podría introducirse este nuevo instrumento en la Ley N. ${ }^{\circ} 7 / 1985$, de 2 de abril, Reguladora de las Bases del Régimen Local (LRBRL). Se trata de una Ley Básica y, por lo tanto, debe limitarse a garantizar un común denominador normativo a partir del cual las comunidades autónomas ejerzan sus competencias, garantizando una regulación esencial y necesaria para proteger el interés general (Sentencias del Tribunal Constitucional [SSTC] N. ${ }^{\circ} 48 / 1988$ y N. ${ }^{\circ} 49 / 1988$, de 22 de marzo, N. ${ }^{\circ} 182 / 1988$, de 13 de octubre, y N. ${ }^{\circ}$ 227/1988, de 20 de diciembre). Más allá de eso, sería un exceso ${ }^{24}$. En consecuencia, la regulación básica estatal se limitaría a garantizar un común denominador normativo a partir del cual las comunidades autónomas podrían ejercer sus competencias, garantizando una regulación esencial y necesaria para proteger el interés general. A su vez, los ayuntamientos aprobarían ordenanzas reguladoras y cada entidad establecería sus normas detalladas de funcionamiento en sus propios Estatutos.

¿Qué debería ser básico? En primer lugar, el reconocimiento de la posibilidad de constituir CAPIEs. En segundo término, habría que definir el régimen jurídico mínimo de estas entidades y sentar las bases del procedimiento para su constitución. Por lo tanto, desde el punto de vista sustantivo, habría de establecerse la adscripción obligatoria a estas entidades, su vigencia temporal, su funcionamiento democrático y el pago de una cuota obligatoria por parte de todos sus miembros. Desde el punto de vista formal, habrían de señalarse unos requisitos mínimos en cuanto al procedimiento (similar al de las asociaciones), el reconocimiento administrativo (autorización por el Pleno del Ayuntamiento) y la inscripción en registro correspondiente (municipal/autonómico) para la adquisición de personalidad y capacidad jurídica plena. Finalmente, en tercer lugar, la Ley Básica remitiría a las comunidades autónomas, a los ayuntamientos y a los estatutos de la Entidad la regulación detallada de la figura.

24 Como consecuencia del carácter de Ley Básica de la LRBRL: por una parte, la legislación autonómica no podrá vulnerar dichas bases; pero, por otra, las bases no podrán descender a detalles o pormenores impropios de su naturaleza de tales, ya que eso supondría una traba para la facultad legislativa de desarrollo reconocida a las comunidades autónomas. 


\section{Pertenencia obligatoria y libertad de asociación: El respeto a la LIBERTAD POSITIVA DE CREAR OTRAS ASOCIACIONES CON FINES PRIVADOS}

El Tribunal Constitucional español (TC) señala que la adscripción obligatoria a una entidad corporativa no puede ir acompañada de una prohibición paralela o impedimento de asociarse libremente. Esto es, no puede quedar afectada la libertad de asociación en su sentido originario o positivo (el límite externo, según la Sentencia del Tribunal Constitucional [STC] N. ${ }^{\circ} 132 / 1989$, de 18 de julio).

El régimen legal de las CAPIEs previsto en esta propuesta cumple claramente con el primero de los criterios de constitucionalidad, puesto que la adscripción obligatoria a estas comunidades no imposibilita el paralelo y libre ejercicio del derecho de asociación por parte de sus miembros. En la medida en que las CAPIEs no ejercerían monopolio representativo alguno del sector empresarial que desarrolla su actividad económica en las áreas objeto de promoción, se respeta la libertad de asociación en su sentido originario, positivo o externo. Las CAPIEs no podrían imponerse por Ley como forma de gestión de las áreas urbanas de promoción empresarial, sino que su creación debe hacerse depender de la iniciativa empresarial, exigiendo la expresión de la voluntad mayoritaria de los afectados expresada de manera inequívoca con carácter previo y, en este sentido, se respetaría, en todo caso, la libertad positiva de crear cualesquiera otras asociaciones con fines privados.

No aparece realmente afectado el derecho de asociación, sino desarrollado un régimen de autoadministración corporativa en materia de gestión de determinadas áreas urbanas, que se encuentra respaldado en el artículo 52 de la Constitución, en régimen de plena compatibilidad con el contenido esencial del derecho de asociación, en cuanto no restringe la viabilidad de otras asociaciones empresariales que desarrollen su actividad en el mismo ámbito.

\section{LA VERTIENTE NEGATIVA DEL DERECHO DE ASOCIACIÓN: EXCEPCIONALIDAD DE LA CONSTITUCIÓN DE LAS CAPIES}

En segundo lugar, según la jurisprudencia constitucional, el recurso a esta forma de actuación administrativa que es, al propio tiempo y antes que nada, una forma de agrupación social creada ex lege, incluida la previsión de adscripción forzosa, no puede ser convertida en la regla sin alterar el sentido de un Estado social y democrático de derecho basado en el valor superior de libertad (artículo 1.1 de la Constitución Espańola, CE) y que encuentra en el libre desarrollo de la personalidad el fundamento de su orden político (artículo 10.1 C.E.). 
Conforme a la doctrina del alto tribunal español, el segundo límite vendría determinado por la vertiente negativa del derecho de asociación. Desde este perspectiva,

[...] ha de considerarse la adscripción forzosa a esas corporaciones públicas como un tratamiento excepcional respecto del principio de libertad, que debe encontrar justificación, bien en disposiciones constitucionales (así, en el artículo 36 C.E.), bien, a falta de ellas, en las características de los fines de interés público que persigan y cuya consecución la Constitución encomiende a los poderes públicos, de manera que la adscripción forzosa cuente con una base directa o indirecta en los mandatos constitucionales (STC 1 N. ${ }^{\circ}$ 39/1989, de 20 de julio).

La opción por la creación de una CAPIE, en cuanto puntual y particular, puede ser considerada compatible con la Constitución. Los intereses sociales de los titulares de actividades económicas ubicados en las APIEs pueden encauzarse por otras vías, y el recurso a la constitución de una CAPIE se contempla, por lo tanto, de manera excepcional.

Nada impide que los empresarios colaboren de manera informal sobre la base de acuerdos voluntarios, creando asociaciones o perteneciendo a las ya existentes, ahora bien, lo que la regulación permitiría sería que, siempre que una mayoría de esos empresarios voluntariamente así lo decidiera, pudieran crearse comunidades de adscripción obligatoria, para cuya constitución habría de requerirse la aprobación del Ayuntamiento.

Este enfoque democrático ofrece un mecanismo de salvaguarda que asegure la confianza de los afectados en la CAPIE. Además, si en la configuración legal de la CAPIE se contemplara un derecho de veto por parte de los afectados, se reforzaría el carácter democrático de la institución y la confianza del sector empresarial. Al tiempo que se limitaría la posible litigiosidad en torno a la constitución de estas comunidades.

El carácter excepcional de la configuración legal que se hace de estas entidades se ve respaldado porque las CAPIEs tienen carácter temporal. Se constituyen para la gestión y ejecución un Plan de Actuación concreto sobre el área de promoción de las iniciativas empresariales. Al cabo de un tiempo -cinco años es el período de tiempo contemplado con carácter general en las legislaciones de otros países-, se extinguen, a no ser que los afectados decidan democráticamente su continuidad. Esta previsión es, de nuevo, un refuerzo del carácter democrático de estas entidades. De igual modo, debe preverse expresamente que tanto su estructura como su funcionamiento sean democráticos. 


\section{EL LEGISLADOR, DE MANERA EXCEPCIONAL, PUEDE PREVER LA CREACIÓN DE ENTIDADES CORPORATIVAS SIEMPRE QUE SE JUSTIFIQUE SUFICIENTEMENTE EN LA CONSECUCIÓN DE FINES PÚBLICOS}

El tercero de los criterios jurisprudenciales para superar el control de constitucionalidad exige que la adscripción obligatoria a estas corporaciones públicas, en cuanto "tratamiento excepcional respecto del principio de libertad", encuentre suficiente justificación, "[...] ya sea en disposiciones constitucionales, ya sea en las características de los fines de interés público que persigan, de las que resulte, cuando menos, la dificultad de obtener tales fines sin recurrir a la adscripción forzosa a un ente corporativo" (SSTC N. ${ }^{\circ}$ 132/1989, de 8 de julio, N. ${ }^{\circ} 139 / 1989$, de 20 de julio, N. ${ }^{\circ} 113 / 1994$, de 14 de abril, N. ${ }^{\circ} 197 / 1994$, de 4 de julio, y N. ${ }^{\circ} 106 / 1996$, de 2 de junio).

En primer lugar, la adscripción obligatoria a las CAPIEs, en cuanto "tratamiento excepcional respecto del principio de libertad", tiene su justificación en disposiciones constitucionales. Las CAPIEs encuentran su amparo constitucional en el artículo $52 \mathrm{CE}$ que hace referencia a las "organizaciones profesionales que contribuyan a la defensa de los intereses económicos que les sean propios". La STC N. ${ }^{\circ} 18 / 1984$, de 7 de febrero, encuadra a las organizaciones profesionales en la categoría de las entidades de carácter social que, en la medida en que su actividad presenta un interés público relevante, pueden ser ordenadas por el Estado y configuradas como corporaciones de derecho público en cuanto instrumentos de interpenetración entre el Estado y la sociedad (Fundamento jurídico 3 de la STC N. $\left.{ }^{\circ} 18 / 1984\right)$.

Por otra parte, no puede olvidarse que estas entidades se conciben como un instrumento de participación ciudadana. La Constitución española proclama la obligación de los poderes públicos de promover la participación de todos los ciudadanos en la vida política, económica, cultural y social (artículo 9.2 CE). Y, en este orden de cosas, la presente propuesta se dirige precisamente, a promover la participación de una comunidad empresarial en la regeneración urbana.

En segundo término, la relevancia de los fines públicos perseguidos o la dificultad de obtenerlos de otro modo podrían justificar la creación de entidades de derecho público como las CAPIEs. La adscripción obligatoria y la imposición de cuotas, igualmente obligatorias, no podría considerarse improcedente si las funciones públicas asignadas por la Ley a las CAPIEs fueran verdaderamente significativas. Y, por otra parte, la constitucionalidad de la configuración legal de la entidad quedaría salvada si sus fines no pudieran ser atendibles sin necesidad de recurrir a la afiliación forzosa a una corporación de derecho público. 
De la finalidad esencial de las CAPIEs (gestión y ejecución del Plan de Actuación), se colige que los empresarios o propietarios que se encuentren incluidos en el ámbito territorial del área contemplada no pueden sustraerse a la pertenencia a dichas entidades, puesto que, en razón de la finalidad perseguida, ésta viene predeterminada por el desarrollo de actividades económicas o la propiedad de locales susceptibles de aprovechamiento empresarial dentro el ámbito territorial del área. Puesto que todos se beneficiarían de las actuaciones realizadas, todos habrían de contribuir solidaria y equitativamente a su sostenimiento.

Las CAPIEs intentan solucionar los problemas que en la actualidad se derivan de la existencia de free riders en el asociacionismo empresarial (personas que reciben un beneficio por utilizar un bien o un servicio, pero no pagan por él). Se pretende evitar que haya empresas de la zona que se beneficien de las inversiones o gastos realizados por los miembros voluntarios de la asociación, pero que no contribuyen económicamente a la misma. Sin la adscripción obligatoria, los problemas de financiación de estas organizaciones son palmarios. Las cuotas se conciben como el instrumento jurídico de financiación de los gastos inherentes a las actuaciones dinamizadoras que se repercuten en los empresarios o propietarios de los locales afectados. Gracias a ellas podrían sufragarse los costes de funcionamiento y los servicios prestados por la CAPIE.

Si se hiciese potestativa la pertenencia a las CAPIEs se vería seriamente cuestionada su viabilidad y con ella la consecución de los fines públicos que tienen encomendados. La adscripción obligatoria a estas entidades supone sin duda una excepción al principio de libertad de asociación constitucionalmente garantizada, y como tal excepción tiene que ser suficientemente justificada. Dicha justificación se encuentra en los fines de interés público que persiguen las CAPIEs, que no serían realizables, o al menos lo serían de forma harto difícil, en el caso de que la adscripción de los miembros de las CAPIEs no fuese obligatoria.

La normativa estatal determinará los fines de las CAPIEs, que habrán de ser concretados en la normativa autonómica. En todo caso, habrán de ser considerados fines esenciales de estas entidades el establecimiento y gestión de servicios en beneficio del APIE y la colaboración con la administración pública en cuanto al ejercicio de funciones que afecten al APIE. Estaríamos, por lo tanto, ante intereses que cabe calificar como públicos y no meramente sectoriales. La enumeración que realice la normativa de desarrollo autonómico de los cometidos de las CAPIEs habrá de permitir apreciar la relevancia pública de estos fines o la imposibilidad o dificultad de alcanzarlos mediante otros instrumentos y deberá servir de fundamento a la estructuración de los intereses de este sector económico en forma de 
corporación de derecho público de adscripción y sostenimiento obligatorio.

Si se analizan los ámbitos de actuación y los fines de estas organizaciones es fácilmente deducible que trascienden los meramente particulares para entroncar, sin ningún género de dudas, con los generales.

El objetivo primordial de su actuación es conseguir revitalizar económicamente la zona, de la que evidentemente no sólo se benefician quienes desarrollan sus actividades empresariales en ella, sino todos aquellos que la habitan o la transitan. Las CAPIEs son un vehículo para desarrollar inversiones adicionales destinadas a fortalecer la economía local. Desde que se crearan en el año 2005, hay en torno a 180 BIDs en el Reino Unido y alrededor de un tercio han sido recientemente renovados, lo que indica que algo está funcionando (Portas 2011). Una encuesta realizada el ańo pasado en el Reino Unido reveló que los BIDs de todo el país tenían la capacidad de generar inversión total de alrededor de $£ 97.000 .000$ al ańo para el desarrollo empresarial y la regeneración urbana (British BIDs 2013). Ésta es una prueba del compromiso de las empresas para invertir en sus áreas locales (Portas 2011:21).

En el ámbito del derecho comparado, donde este tipo de organizaciones tienen una dilatada experiencia, puede observarse que los fines que tienen encomendados son, entre otros, los siguientes: 1) fortalecimiento de la competitividad de los centros urbanos; prestación de servicios de marketing comercial (señalización específica, publicidad, mejora de la imagen, revitalización de determinadas zonas a los efectos de promocionar el turismo, incrementando el atractivo de la zona); 2) desarrollo de políticas de retención y captación de negocio (guías de los principales lugares de interés de una determinada zona mejorando las condiciones que propicien la inversión, el crecimiento y la competitividad); 3) mejoras de la calidad del espacio urbano (pavimentación, limpieza, iluminación, mobiliario urbano, mejoras en zonas verdes y otras análogas; 4) mantenimiento (recogida de basuras, limpieza de grafitis, trabajos de jardinería); 5) vigilancia y seguridad; 6) organización del transporte y estacionamiento; y 7) prestación de servicios sociales (creación y colaboración con programas de ayuda a los sin techo y programas de servicios para los jóvenes).

Aunque algunos de estos fines puedan calificarse como sectoriales, en su mayoría atienden a finalidades de carácter público. Todas las actividades que desarrollan -es importante reiterarlo- tienen que ser complementarios a las proporcionadas por las administraciones públicas. Por lo tanto, los servicios prestados no pueden sustituir a los servicios públicos. 
En definitiva, tal y como concebimos a estas entidades, se dirigen no sólo a la salvaguarda de intereses privados mediante la prestación de servicios a las empresas y propietarios, sino también a la consecución de fines esencialmente públicos como la dinamización y regeneración de la zona urbana sobre la que actúan, además de configurarse como órganos de colaboración con la administración local. En este sentido, debería preverse la participación de representantes de la Administración en los órganos de gobierno de la entidad.

\section{Proceso de Creación: ¿QUUiÉn Debe Tener la InICIATIVA? ¿QUÉ QUÓRUM HABRÍA DE EXIGIRSE?}

Debe insistirse en que el régimen legal conjeturado no obliga a nadie a crear una CAPIE. La iniciativa para su creación ha de ser privada. Se constituirían de manera voluntaria, por la aquiescencia mayoritaria de los llamados a ser miembros de la entidad (hay, por lo tanto, un pactum associationis original). En este sentido, nos hallamos ante entidades que tendrían un carácter bifronte. Por una parte, serían fruto de la decisión libre de los afectados, cuya opción mayoritaria por la constitución de la entidad habrían de manifestar formalmente, y que se crearían para la obtención de los fines, no autónomamente elegidos, sino fundamentalmente determinados por la Ley, como luego se verá. Y, por otra, serían el resultado de una decisión de los poderes públicos, que una vez constatada la voluntad mayoritaria de los afectados, esto es, confirmada la existencia del pactum associationis original, procederían a crear la entidad.

Así pues, las CAPIEs no serían creadas por decisión unilateral de la Administración, sino que nacerían de la decisión de los empresarios y propietarios de locales incluidos en un determinado ámbito territorial.

La normativa estatal que regulase estas entidades podría prever la obligatoriedad de constituir CAPIEs si así lo solicitara al menos el cincuenta por ciento de los empresarios y/o propietarios de la zona afectada, que representen al menos un cincuenta por ciento de las cuotas que deban ser satisfechas. Su creación y sus estatutos habrán de ser aprobados posteriormente por el Ayuntamiento. La medida, partiendo de los postulados del carácter voluntario, facilita la tarea de gestión impidiendo que la oposición de uno solo de los propietarios, o un sector minoritario de los mismos, bloqueen lo que puede ser una opción deseable para los mayoritarios, en una equiparación con el régimen de las juntas de compensación, en el ámbito de la gestión urbanística. La elección de este sistema, según la legislación estatal (artículo 158 del Reglamento de Gestión Urbanística, RGU), requiere del acuerdo de los propietarios que representen al menos el sesenta por ciento del suelo de la unidad de 
actuación, si bien algunas comunidades autónomas han reducido este porcentaje para facilitar su elección.

La regulación que se propone presenta también muchas concordancias con la de las denominadas entidades de conservación en el ámbito de la gestión urbanística, cuya constitucionalidad no se discute. Estas entidades constituyen una de las clases de entidades urbanísticas colaboradoras a través de las cuales los interesados pueden participar en la gestión urbanística, junto a las juntas de compensación y las asociaciones administrativas de propietarios (artículo $24 \mathrm{RGU}$ ). Se trata de personas jurídicas, dotadas de personalidad jurídica propia e independiente de la de los miembros que la integran (artículo 26.2 RGU) y, en consecuencia, con su propia capacidad jurídica, capacidad de obrar y capacidad procesal; como tales cuentan con su propio régimen de obligaciones y responsabilidades, así como con su peculiar régimen estatutario que define su estructura y funcionamiento dentro del marco legal preestablecido, que se ha de integrar con la correspondiente publicidad del acto de su constitución, así como con inscripción en un Registro Público, a partir de cuyo momento adquieren la personalidad jurídica.

También se ha pronunciado el Tribunal Constitucional sobre la constitucionalidad de las comunidades de usuarios, contempladas en la Ley de Aguas (STC N. ${ }^{\circ}$ 227/1988, de 29 de noviembre). Se trata igualmente de corporaciones de derecho público, "[...] cuya finalidad no es otra que la gestión autónoma de los bienes hidráulicos necesarios para los aprovechamientos colectivos de los mismos, en régimen de participación por los interesados". Sin embargo, junto a esta función pública, en las Comunidades de Regantes no cabe desconocer la existencia de un interés netamente privado, de carácter profesional, que estuvo presente en sus orígenes históricos, aunque la evolución a lo largo del tiempo de estas agrupaciones se haya caracterizado por una tendencia a acentuar sus funciones públicas, pero sin llegar a desnaturalizar o eliminar su carácter de agrupación privada para satisfacer los intereses de los comuneros. Por ello, las comunidades de regantes forman parte de la denominada Administración Corporativa, caracterizados por ser entes dotados de personalidad jurídica a los que la Ley les atribuye la gestión de fines públicos, lo que les convierte en Administraciones Públicas, pero que a la vez que satisfacen los intereses privados de sus miembros, siendo pues de naturaleza mixta pública-privada, al igual que otro tipo de entidades asociativas previstas en el ordenamiento como español son los colegios profesionales, las cámaras de comercio, industria y navegación y las extinguidas cámaras de la propiedad urbana.

Estas asociaciones deben ser consideradas como distintas de las previstas en el artículo $22 \mathrm{CE}$, que no comprendería “[...] el derecho de 
constituir asociaciones para el ejercicio de funciones públicas de carácter administrativo relativas a un sector de la vida social"; la peculiaridad de estas asociaciones legitimaría los específicos requisitos legales en cada caso previstos.

En cuanto al procedimiento legal aplicable para la constitución de las CAPIEs, como repetidamente se ha señalado, se determina una constitución voluntaria (como también se hace por la normativa urbanística en el caso de las juntas de compensación o las entidades de conservación). Y, así, la iniciativa de constitución partiría de los empresarios/propietarios de los locales de negocios del área. Los propios interesados asumirían el protagonismo en la tramitación, debiendo formalizar y acreditar las reuniones necesarias para concretar la voluntad de constituir una CAPIE, así como elaborar el texto de los futuros estatutos que determinen el régimen jurídico de la misma o presentar un Plan de Actuación para la zona acompañado de un proyecto de financiación. Los trámites concretos a seguir habrán de ser determinados por la legislación autonómica ${ }^{25}$.

En cuanto al régimen de constitución de las CAPIEs, al moverse en un campo como el corporativo diferenciado del derecho de asociación,

25 Cada Comunidad Autónoma aprobaría su propia regulación en la que se establecería una regulación detallada del procedimiento para la constitución de estas entidades, que idealmente, habría de contar con tres fases. En la fase inicial se prevería: la propuesta de creación de un APIE a partir de la iniciativa de algunos de los empresarios (comerciantes al por menor, proveedores de servicios, profesionales liberales) y los propietarios de los inmuebles de la zona, que actuarán como Comisión Promotora; la definición del área geográfica en la que se desarrollarán las medidas propuestas; la elaboración de un proyecto del Plan de Actuación, junto con la financiación prevista. La segunda fase de concreción contemplaría: la solicitud formal de los interesados dirigida al Ayuntamiento; la apertura de un período de información pública y la negociación con el Ayuntamiento de un convenio de colaboración. Por último, en la fase de decisión se sometería a votación la propuesta. Para que ésta fuera ratificada, habría de obtener el respaldo mayoritario de los afectados. Podría determinarse la necesidad de conseguir la mayoría de votos de al menos el 50\% de los titulares de las actividades empresariales de la zona prevista. O podría establecerse la necesidad de una doble mayoría, exigiendo, además, que la mayoría represente una mayoría de las cuotas. Cada Comunidad Autónoma determinaría las reglas por las que se regiría el proceso de votación (información pública, duración de la campaña de difusión de la propuesta, determinación del censo, quórum, determinación de una ponderación del voto en función de la superficie o del valor catastral de los establecimientos). Una vez aprobada la propuesta por los interesados, se constituiría la CAPIE mediante un acuerdo del Ayuntamiento; se inscribiría la Entidad en el correspondiente Registro; se aprobarían los Estatutos y establecerían los órganos de gobierno de la entidad. Finalmente, habría de contemplarse la suscripción de convenios de colaboración entre el Ayuntamiento y la entidad constituida. Dichos convenios contemplarán necesariamente la participación de representantes de la Administración local en los órganos de gestión de la comunidad, así como el control municipal de su presupuesto y Plan de Actuación y la aportación municipal, en su caso. 
aparece plenamente justificada la intervención administrativa que, de un lado, constata la realidad del grupo social homogéneo sobre el que ha de configurarse la corporación, y de otro, controla la legalidad de su estructura organizativa y estatutaria como requisitos ambos previos al ejercicio de las funciones jurídico-públicas que se les van a conferir.

\section{RÉGIMEN DE FINANCIACIÓN}

Como se apuntaba en la primera parte de este artículo, para que la maquinaria del BID funcione, es imprescindible que todos los propietarios/ empresarios de la zona delimitada contribuyan de manera obligatoria a su sostenimiento.

Algunas de las propuestas que se han hecho para la introducción de los BIDs en España han optado por la vía de crear un nuevo tributo. Bien, mediante el establecimiento de una nueva contribución especial (Proposición de Ley del PSC 2012. Ver Parlament de Catalunya 2012) o bien mediante la constitución de asociaciones administrativas de contribuyentes que estarían obligadas a pagar contribuciones especiales al Ayuntamiento (Ayuntamiento de Madrid 2014b). En el ámbito del derecho comparado, sabemos que las fórmulas de financiación varían de un país a otro.

Las contribuciones especiales son tributos potestativos cuyo hecho imponible consiste, considerando los artículos 2.2.b) de la Ley General Tributaria y 28 del Texto Refundido de la Ley de las Haciendas Locales (TRLHL), en la obtención por el sujeto pasivo de un beneficio o de un aumento de valor de sus bienes como consecuencia de la realización de obras públicas o del establecimiento o ampliación de servicios públicos, de carácter local, por las entidades respectivas.

El artículo 36 del TRLHL, bajo el título colaboración ciudadana, permite que los propietarios o titulares afectados por las obras puedan constituirse en asociación administrativa de contribuyentes y promover la realización de obras o el establecimiento o ampliación de servicios por la entidad local, comprometiéndose a sufragar la parte que corresponda aportar a ésta cuando su situación financiera no lo permitiera, además de la que les corresponda según la naturaleza de la obra o servicio ${ }^{26}$.

Una de las recientes propuestas por parte del Ministerio de Economía - de acuerdo con la información aparecida en la prensa (El País 2014b)_

26 Para la constitución de las asociaciones administrativas de contribuyentes, el acuerdo deberá ser tomado por la mayoría absoluta de los afectados, siempre que representen, al menos, los dos tercios de las cuotas que deban satisfacerse. 
planea la creación de áreas comerciales urbanas (ACU), que se financien mediante una bonificación de hasta el $95 \%$ de la cuota íntegra del Impuesto de Bienes Inmuebles (IBI), de la que se beneficiarían los inmuebles ubicados en la zona. Parece que está previsto que el Ayuntamiento, que es el encargado de recaudar este impuesto sobre la propiedad, se quede con el $5 \%$ de la recaudación y entregue el resto a la entidad que gestiona la ACU para que financie sus actividades y servicios. Sin conocer más detalles de esta propuesta y aún a riesgo por lo tanto de emitir un juicio precipitado e infundado, resulta muy criticable una medida que consiste en que una comunidad empresarial o de propietarios sea la encargada de gestionar el dinero público -el 95\% de la recaudación del IBI en la zona- utilizándolo como mejor convenga a sus intereses. Al tiempo, esta propuesta -que dice inspirarse en los BIDs- no tiene nada que ver con la filosofía del modelo, que consiste -lo hemos repetido muchas veces- en que una comunidad empresarial o de propietarios decide pagar más para obtener a cambio más servicios. Sin embargo, en este caso, no se hacen aportaciones extra, sino que lisa y llanamente, en contra de los más elementales principios de justicia tributaria, parece que se permite que unos pocos financien con sus propios impuestos las actividades y servicios dirigidas a revitalizar, promocionar y mejorar la zona en que desarrollan sus negocios.

A mi juicio, respecto a la financiación de este tipo de entidades, sería preferible no introducir un nuevo tributo en el sistema de financiación local ni establecer tampoco una bonificación como la descrita en el párrafo anterior, sino habilitar la posibilidad de que una comunidad empresarial decida democráticamente en su ámbito y para un conjunto de actividades a desarrollar, previamente conocidas, tasadas y con un coste presupuestado, contribuir económicamente al funcionamiento de la entidad.

Todos conocemos perfectamente el funcionamiento de una comunidad de vecinos. Pues bien, el de esas organizaciones no diferiría mucho del previsto en la Ley de Propiedad Horizontal, en la que se establece la obligación de cada propietario de contribuir, de acuerdo con la cuota de participación establecida, a los gastos generales para el adecuado sostenimiento del inmueble, sus servicios, cargas y responsabilidades. También serán costeadas por los propietarios las derramas para el pago de mejoras en el inmueble.

Descartada, por lo tanto, la vía de creación de una nueva figura impositiva, los recursos de las CAPIEs provendrían mayoritariamente de las aportaciones obligatorias de sus miembros. Además, cabrían otras vías de financiación añadidas y secundarias: contribuciones voluntarias, donaciones y subvenciones o ayudas públicas de las Administraciones públicas (el convenio de colaboración puede fijar la aportación municipal). 
La CAPIE nace de manera democrática para financiar un Plan de Actuación en una zona urbana concreta por un período de tiempo determinado (máximo 5 años). Es lógico que quienes van a beneficiarse directamente del proyecto contribuyan a sufragar los gastos. Las CAPIEs serán desarrolladas, gestionadas y financiadas por el sector empresarial mediante una contribución económica obligatoria sobre la que los afectados tendrán que votar a favor antes de que la entidad sea constituida. Por lo tanto, cada responsable de contribuir a la CAPIE estará capacitado para votar si la propuesta de creación de una CAPIE sigue adelante o no. Las CAPIEs no constituyen un régimen permanente, como sería propio de los organismos puramente públicos, sino que son un sistema de participación de los empresarios y propietarios en la gestión de los centros urbanos mediante la financiación de un concreto Plan de Actuación dirigido a dinamizar, regenerar y desarrollar el área urbana en que se desenvuelven sus actividades económicas. A tal fin, los interesados han de satisfacer unas cuotas, lo cual no deriva tanto de la mera condición de miembro de la entidad cuanto de la efectividad de los gastos.

Estas cuotas no pueden ser consideradas tributos, sino ingresos de derecho público de naturaleza parafiscal (exacción parafiscal obligatoria).

Las cuotas serían la parte proporcional de los costes de financiación del Plan de Actuación, que debe soportar cada titular de las actividades económicas integradas en el área de promoción económica. Su importe será distribuido tal y como establezcan los Estatutos reguladores de la CAPIE. Los estatutos podrían fijar exenciones y bonificaciones. ¿Cómo se calcularía la cuota? Sin lugar a dudas, debería establecerse un reparto proporcional y equitativo. Podrían establecerse coeficientes en función de la superficie de los inmuebles, su valor catastral, número de trabajadores, entre otros

¿Y quién recaudaría? Los entes responsables de la recaudación de las cuotas habrían de ser distintos, dependiendo de si la cuota se encuentra o no en fase de apremio. La gestión y el cobro de las cuotas corresponderían, en período voluntario a la CAPIE y la gestión en vía de apremio al Ayuntamiento del cual dependa. En definitiva, los Ayuntamientos serían los responsables de ejecutar el apremio, mientras que, en tanto los recibos de las cuotas no sean apremiados, el único ente responsable de su recaudación sería la propia CAPIE. 


\section{CONCLUSIONES}

Ante la fascinación que el modelo de los BIDs está suscitando en el panorama actual de la gestión de centros urbanos en España, conviene no perder de vista que la recepción de un modelo no puede hacerse alocadamente, dejándose llevar de una moda o pensando exclusivamente en sus aparentes bondades y haciendo caso omiso de sus consecuencias perniciosas.

En la práctica legislativa es extremadamente común el transplante de normas individuales o de una buena parte de un sistema jurídico de un país a otro. Ahora bien, no siempre las medidas y herramientas foráneas propuestas se aclimatan al sistema jurídico y a las instituciones autóctonas (Watson: 1974: 21). Desde el punto de vista jurídico, trasladar esa fórmula al ordenamiento jurídico español implicaría importantes reformas legislativas que hicieran posible que todos los establecimientos comerciales y de servicios ubicados en una determinada zona urbana pertenecieran obligatoriamente a la organización creada y que obligatoriamente contribuyeran a su financiación, mediante el pago de contribuciones adicionales. Téngase presente que eso supondría una suerte de publificación de estas entidades, lo que generaría notables dificultades institucionales y organizativas. Igualmente, en la implantación del modelo BID, habría de exigirse una ineludible acción pública en la recaudación de los fondos y en el control de los gastos. Y supondría, además, muchas otras cosas, entre ellas, la necesidad de redefinir el papel que el sector público y el sector privado desempeñan en el espacio público, pues no siempre las actividades y los objetivos de ambos serán idénticos. 


\section{REFERENCIAS}

Amin, Ash y Thrift, N. (1995). Globalisation, Institutional 'Thickness' and the Local Economy. En Healey, P. et al. (Eds.), Managing Cities: The New Urban Context. Chichester: Wiley.

Ayuntamiento de Madrid. (2014a). Boletín Oficial, 7.183, 9 de junio. Madrid: Ayuntamiento de Madrid.

(2014b). Ordenanza de Dinamización de Actividades en Dominio Público Mediante la que se Crean las Zonas De Iniciativa Emprendedora. Madrid: Ayuntamiento de Madrid.

Barr, H. (1997). More like Disneyland: State Action, 42 U.S.C. $\$ 183$, and Business Improvement Districts in New York. Columbia Human Rights Review, 28, 393-429.

Benson, J. (2006). Regulating Street Vendors in New York City: Case Studies. Tesis (Faculty of Architecture and Planning), Columbia University, Nueva York, Estados Unidos.

Borja, J. y Castells, M. (1996). Local and Global: Management of Cities in the Information Age. Londres: Earthscan.

Bradford, N. (2003). Public-Private Partnership? Shifting Paradigms of Economic Governance in Ontario. Canadian Journal of Political Science, 36 (5), 1020-1022.

Brenner, J. (2010). Private Initiatives in German Urban Development Policy. Urban Research \& Practice, 3 (2), 219-228.

Brenner, N. y Theodore, N. (2002). Cities and the Geographies of Actually Existing Neoliberalism. Antipode 34 (3), 349-379.

Brenner N., Peck, J. y Theodore, N. (2010). Variegated Neoliberalization: Geography, Modalities, Pathways. Global Networks, 10 (2), 182-222.

Briffault, R. (1999). A Government for Our Time? Business Improvement Districts and Urban Governance. Columbia Law Review, 99 (2), 365477.

The Business Improvement District Comes of Age. Drexel Law Review, 3, 19-33.

Brinkerhoff, J. M. (2002). Government-NGO Partnership: A Defining Framework. Public Administration and Development, 22 (1): 19-30. 
Brinkerhoff, D. W. y Brinkerhoff, J. M. (2011). Public-Private Partnerships: Perspectives on Purposes, Publicness, and Good Governance. Public Administration and Development, 31 (1), 2-14.

British BIDs. (2013). Nationwide BIDs Survey 2013. Disponible en http://www.britishbids.info/LinkClick.aspx?fileticket=G0SyvX_ AcGs\%3d\&tabid=172 [29-08-2014].

Brooks, L. (2008). Volunteering to be Taxed: Business Improvement Districts and the Extra-Governmental Provision of Public Safety. Journal of Public Economics, 92, 388-406.

Clough, N. L. y Vanderbeck, R. M. (2006). Managing Politics and Consumption in Business Improvement Districts: The Geographies of Political Activism on Burlington, Vermont's Church Street Marketplace. Urban Studies, 43 (12), 2261-2284.

Congreso de los Diputados (2012). Boletín Oficial de las Cortes Generales, Serie D, Núm. 68, 3 de abril. Madrid: Congreso de los Diputados.

. (2014). Boletín Oficial de las Cortes Generales, Serie D, Núm. 431, 31 de marzo. Madrid: Congreso de los Diputados.

Cook, Ian R. (2008). Mobilising Urban Policies: The Policy Transfer of US Business Improvement Districts to England and Wales. Urban Studies, 45 (4), 773-795.

. (2009). Private Sector Involvement in Urban Governance: The Case of Business Improvement Districts and Town Centre Management Partnerships in England. Geoforum, 40, 930-940.

(2010). Policing, Partnerships and Profits: The Operations of Business Improvement Districts and Town Center Management Schemes in England. Urban Geography, 31 (4), 453-478.

Cook, I. R. y Ward, K. (2012). Conferences, Informational Infrastructures and Mobile Policies: The Process of Getting Sweden 'BID Ready'. European Urban and Regional Studies, 19 (2), 137-152.

Davies, M. S. (1997). Business Improvement Districts. Journal of Urban and Contemporary Law, 52, 187-223.

Department for Communities and Local Government. (2013). Property Owners and Business Improvement Districts: Formalising the Role of Property Owners, Who are not Ratepayers, in Business Improvement 
District Schemes. Londres: Government UK.

Eick, V. (2012). The Co-Production of Purified Space: Hybrid Policing in German Business Improvement Districts. European Urban and Regional Studies, 19 (2), 121-136.

(2014). Emerging Semi-States: The BIDisation of German Cities. Ponencia presentada en el encuentro Integrating interests: future-proofing city centre retail economies?, 31 de marzo, University of Sheffield, Reino Unido. Disponible en: http://www.sheffield.ac.uk/ polopoly_fs/1.366953!/file/VolkerEick_EmergingSemi-States.pdf [28-08-2014].

El País. (2014a). El Gobierno Planea Abrir la Gestión de los Barrios a Entidades Privadas. El País, 23 de junio.

. (2014b). Los Comerciantes no Pagarán Más por los Barrios Premium. El Pais, 1 de julio.

England, K. y Ward, K. (Eds.). (2007). Neoliberalization: States, Networks, Peoples. Oxford: Blackwell, Antipode Book Series.

Fernández Rodríguez, T. (2008). Manual de Derecho Urbanistico. Madrid: El Consultor de los Ayuntamientos (La Ley-Wolters Kluwer).

Friesecke, F. (2006). Revitalization of Urban Areas through Business Improvement Districts (BIDs)-Trends and Expectations for Shrinking Cities. Ponencia presentada en la conferencia Promoting Land Administration and Good Governance. 5th FIG Regional Conference, 8-11 de marzo, Accra, Ghana.

Gross, J. S. (2013). Business Improvement Districts in New York: The Private Sector in Public Service or the Public Sector Privatized? Urban Research \& Practice, Vol. 6, No. 3: 346-364.

Harvey, D. (1989). From Managerialism to Entrepreneurialism: The Transformation in Urban Governance in Late capitalism. Geografiska Annaler Series B: Human Geography, 71 (1), 3-17.

Hernández, T. y Jones, K. (2005). Downtowns in Transition. Emerging Business Improvement Area Strategies. International Journal of Retail and Distribution Management, 33 (11), 789-805.

Hochleutner, B. R. (2003). BIDs Fare Well: The Democratic Accountability of Business Improvement Districts. New York University Law Review, 
$78,374-404$.

Houstoun, L. O. (1999). Business Improvement Districts and Urban Entertainment and Cultural Centers. Washington: American Planning Association.

(2003). Business Improvement Districts. Washington: Urban Land Institute-International Downtown Association.

Hoyt, L. (2006). Importing Ideas: The Transnational Transfer of Urban Revitalization Policy. International Journal of Public Administration, 29, 221-243.

Hoyt, L. y Gopal-Agge, D. (2007). The Business Improvement District Model: A Balanced Review of Contemporary Debates. Geography Compass, 1 (4), 946-958.

Jessop, Bob. (2002). Liberalism, Neoliberalism, and Urban Governance: A State-Theoretical Perspective. Antipode, 34 (3), 453-472.

Johnston, J. M. y Romzek, B. S. (2005). Traditional Contracts as Partnerships: Effective Accountability in Social Service Contracts in the American States. En Grevec, H. (Eds.), The Challenge of Public-Private Partnerships: Learning from International Experience. Northampton: Edward Elgar Publishing.

Katz, Peter (Eds.). (1994). The New Urbanism: Toward an Arquitecture of Community, Nueva York: McGraw Hill.

Kavaratzis, M. (2007). City Marketing: The Past, the Present and Some Unresolved Issues. Geography Compass, 1 (3), 695-712.

Kickert, W. J. M., Klijn, E. y Koppenjan, J. F. M. (2000). Managing Complex Networks: Strategies for the Public Sector. Londres: Sage Publications.

Kreutz, S. (2009). Urban Improvement Districts in Germany: New Legal Instruments for joint Proprietor Activities in AREA DEVELOPMENT. Journal of Urban Regeneration and Renewal, 2 (4), 304-317

Krishna, A. (2003). Partnerships between Local Governments and Community-Based Organizations: Exploring the Scope for Synergy. Public Administration and Development, 23 (4), 361-371.

Lloyd, G., McCarthy, J., McGreal, S. y Berry, J. (2003). Business Improvement Districts, Planning and Urban Regeneration. International Planning Studies, 8 (4), 295-321. 
Lloyd, G. y Peel, D. (2008). From Town Centre Management to the BID Model in Britain: Towards a New Contractualism? En Morçöl, G., Hoyt, L., Meek, J. W., Zimmerman, U. (Eds.), Business Improvement Districts: Research, Theories, and Controversies. Londres: Routledge.

Lovering, J. (1995). Creating Discourses Rather than Jobs: The Crisis in the Cities and the Transition Fantasies of Intellectuals and Policy Makers. En Healey, P. et al. (Eds.), Managing Cities: The New Urban Context. Chichester: Wiley.

Mallett, W. J. (1994). Managing the Postindustrial City: Business Improvement Districts in the United States. Area, 26 (3), 276-287

McCann, E. y Ward, K. (2013). A Multi-Disciplinary Approach to Policy Transfer Research: Geographies, Assemblages, Mobilities and Mutations. Policy Studies, 34 (1), 2-18.

Ministerio de Economía y Competitividad. (2014). Plan Integral de Apoyo a la Competitividad del Comercio Minorista de España 2014, Disponible en http://www.mineco.gob.es/stfls/mineco/comercio/pdf/140425_ PLAN_APOYO_COMERCIO_MINORISTA.pdf [30-08-2014].

Mitchell, J. (1999). Business Improvement Districts and Innovative Service Delivery, Nueva York The PricewaterhouseCoopers Endowment for the Business of Government.

. (2008). Business Improvement Districts and the Shape of the City. Albany: State University of New York Press.

Morçöl, G. (2010). Center City District: A Case of Comprehensive Downtown BIDs. Drexel Law Review, 3, 271-285.

Morçöl, G., Hoyt, L., Meek, J. y Zimmermann, U. (Eds.). (2008). Business Improvement Districts: Research, Theories, and Controversies. Boca Raton: CRC Press.

Morçöl, G. y Wolf, J. F. (2010). Understanding Business Improvement Districts: A New Governance Framework. Public Administration Review, 70 (6), 906-913.

New York City Department of Small Business Services. (2003a). Starting a Business Improvement District. A Step-By-Step Guide, New York City. Disponible en:http://www.nyc.gov/html/sbs/downloads/pdf/bid_ guide_complete.pdf [10-08-2014]. 
(2003b). Introduction to Business Improvement District, New York City. Disponible en http://www.nyc.gov/html/sbs/downloads/ pdf/bid_brochure.pdf [10-08-2014].

Parada Vázquez, R. (1999). Derecho Administrativo. Organización y Empleo Público. Madrid: Marcial Pons.

Partido Socialista Obrero Español (PSOE). (2008). Motivos para Creer. Porgrama Electoral. Elecciones Generales 2008. Madrid: Partido Socialista Obrero Español.

Peck, J. y Tickell, A. (2002). Neoliberalizing Space. En Brenner N. y Theodore N. (Eds.), Spaces of Neo-Liberalism: Urban Restructuring in North America and Western Europe. Oxford: Blackwell Publishing.

Peck, J. y Theodore, N. (2010). Mobilizing Policy: Models, Methods, and Mutations. Geoforum, 41 (2), 169-174.

Peyroux, E., Pütz, R. y Glasze, G. (2012). Business Improvement Districts (BIDs): The Internationalization and Contextualization of a Travelling Concept. European Urban and Regional Studies, 19 (2), 111-120.

Portas, M. (2011). The Portas Review: An Independent Review into the Future of Our High Streets. Londres: Department for Business, Innovation and Skills.

Ratcliffe, J., Williams, B. y Branagh, S. (1999). Managing and Financing Urban Regeneration. A Preliminary Study on the Prospective Use of Business Improvement Districts and Tax Increment Finance Districts in Ireland. Dublin: Dublin Institute of Technology.

Ratcliffe, J. y Branagh, S. (2004). Enhancing the Vitality and Viability of Town and City Centres. The Concept of the Business Improvement District in the Context of Tourism Enterprise. Property Management, 22 (5), 377-395.

Rovira Lara, A. (2011). ¿'Mito o Realidad? La Situación de los Centros Comerciales Urbanos en España”. Ponencia presentada en el Encuentro Nacional Presente y futuro de los centros comerciales urbanos en España, 5 de julio, Madrid, España.

Villarejo Galende, H. (2007). Micrópolis Comerciales: Ética Y Estética de las Calles Comerciales. Ponencia presentada en el Foro Internacional Ética y Estética de la Ciudad, 17-19 de octubre, Puebla, México. 
. (2008a). Equipamientos Comerciales: Entre el Urbanismo y la Planificación Comercial, Granada: Comares.

. (2008b). Espacios Públicos Gobernados Privadamente. Papeles de Relaciones Ecosociales y Cambio Global, 101, 101-116.

Ward, K. (2006). 'Policies in Motion', Urban Management and State Restructuring: The Trans-Local Expansion of Business Improvement Districts. International Journal of Urban and Regional Research, 30 (1), 54-75.

. (2007). Business Improvement Districts: Policy Origins, Mobile policies and Urban Liveability. Geography Compass, 1 (3), 657-672.

Ward, K. y Cook, I. R. (2014). Business Improvement Districts in the UK: Territorialising a 'Global' Model? Imagining Urban Futures Working Paper 13. Disponible en http://research.northumbria.ac.uk/ urbanfutures/wp-content/uploads/2012/03/Ward-and-Cook-2014BIDs-in-the-UK.pdf [28-08-2014].

World Bank. 2005. Exploring Partnerships between Communities and Local Governments in Community Driven Development: A Framework. Report No. 32709-GLB. Washington: World Bank, Environmentally and Socially Sustainable Development Network.

Watson, A. (1974). Legal Transplants. An Approach to Comparative Law, Edinburgo: Scottish Academic Press.

Recibido: 08-12-2014

Aceptación de la versión final: 22-12-2014 